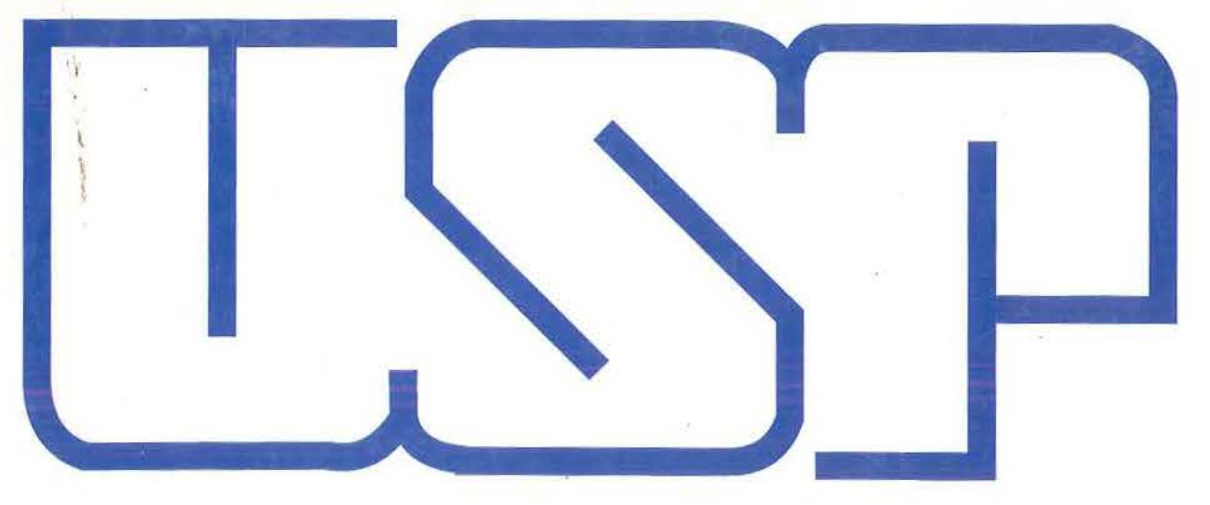

O Efeito do Ultra-Som Terapêutico na Vascularização Pós Lesão Muscular Experimental em Coelhos

Autor: Valdeci Carlos Dionísio Orientador: Prof. Dr. José Batista Volpon

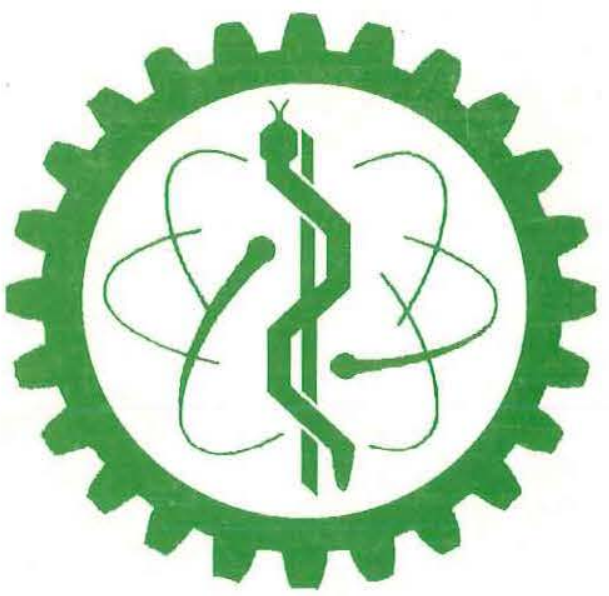

B I OE N GEN H A R I A

USP

Curso de Pós-Graduação Interunidades Bioengenharia

Escola de Engenharia de São Carlos

Faculdade de Medicina de Ribeirão Preto

Instituto de Química de São Carlos 


\title{
O EFEITO DO ULTRA-SOM TERAPÊUTICO NA VASCULARIZAÇÃO PÓS LESÃO MUSCULAR EXPERIMENTAL EM COELHOS
}

\author{
Valdeci Carlos Dionísio
}

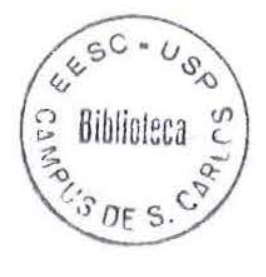

Dissertação apresentada à Escola de Engenharia de São Carlos / Faculdade de Medicina de Ribeirão Preto da Universidade de São Paulo / Instituto de Química de São Carlos, como parte dos requisitos para obtenção do título de Mestre em Bioengenharia

ORIENTADOR: Prof. Dr. José B. Volpon 
\begin{tabular}{|l|} 
Class. $\frac{\text { TESE }}{2010}$ \\
Cut. $\frac{2010}{\text { Tombo }}$ \\
\hline
\end{tabular}

At 1063225

Ficha catalográfica preparada pela Seção de Tratamento da Inform ação do Serviço de Biblioteca - EESC-USP

Dionísio, Valdeci Carlos

D592e O efeito do ultra-som terapêutico na vascularização pós lesão muscular experimental em coelhos / Valdeci Carlos Dionísio. -- São Carlos, 1998 .

Dissertação (Mestrado). -- Área Interunidades em Bioengenharia da EESC/FMRP/IQSC-Universidade de São Paulo, 1998.

Orientador: Prof. Dr. José B. Volpon.

1. Ultra-som. 2. Angiogênese. 3 Músculo esquelético. 4. Lesão experimental. I. Título. 
À minha esposa e filhos, que compreenderam os momentos de ausência. 


\section{Agradecimentos}

Ao Prof. Dr. José B. Volpon, pela segura e excelente orientação, participação e empenho na elaboração deste trabalho.

Às minhas chefes, Érika Lopes da Silva e Renata Licursy Nogueira, pelo apoio e incentivo.

À amiga, Denise Ferreira de Menezes, pela colaboração, apoio e incentivo.

À Bioset Industria de Tecnologia e Eletrônica Ltda, pela doação e adaptação do equipamento.

Ao Prof. Dr. José Baptista P. Paulin, por ceder as instalações e facilidades do Laboratório de Bioengenharia.

Aos funcionários Francisco Carlos Mazzocato, Luis Henrique Alves Pereira, Antônio Carlos Shimano, Carlos Alberto Moro e Sônia Aparecida Rodrigues da Silva do Laboratório de Bioengenharia da Faculdade de Medicina de Ribeirão Preto da Universidade de São Paulo, pela amizade e prontidão de seus serviços.

À Pós-graduação das Interunidades Bioengenharia EESC/FMRP/IQSC USP, pela oportunidade de realizar este trabalho. 


\section{SUMÁRIO ${ }^{1}$}

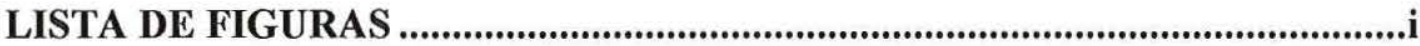

LISTA DE ABREVIATURAS E SIGLAS ......................................................... ii

LISTA DE SÍMBOLOS........................................................................................ iii

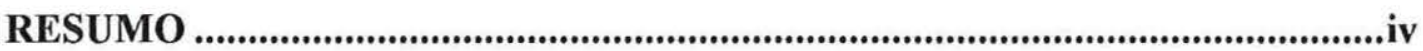

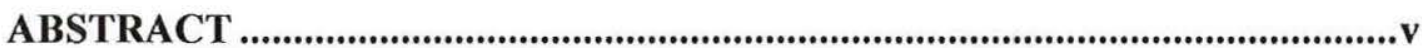

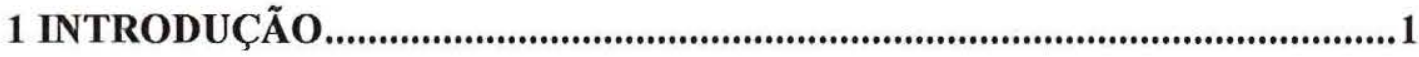

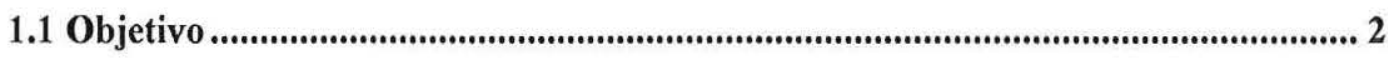

1.2 Ultra-som

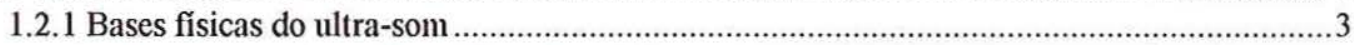

1.2.1.1 Características das ondas ultra-sônicas ....................................................................

1.2.1.2 Produção e transmissão do ultra-som .................................................................... 5

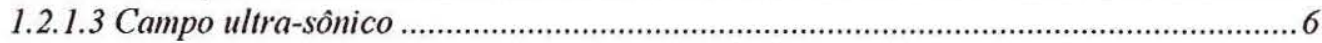

1.2.1.4 Parâmetros do campo ultra-sônico......................................................................... 7

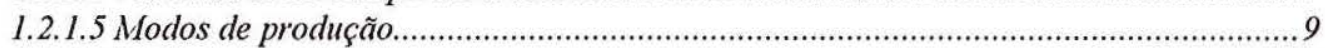

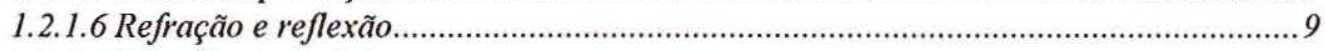

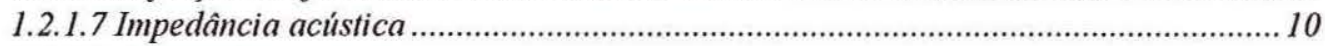

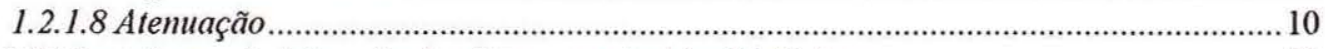

1.2.2 Mecanismos de interação do ultra-som e tecidos biológicos.............................................11

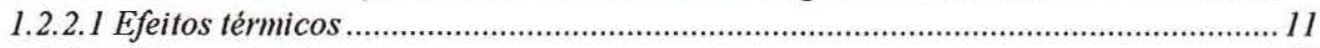

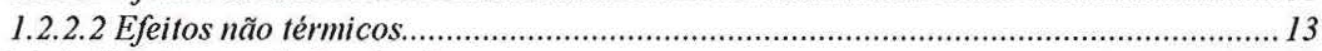

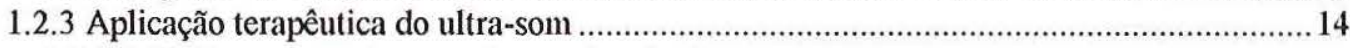

1.2.3.1 Efeitos sobre a temperatura e circulação ……....................................................... 14

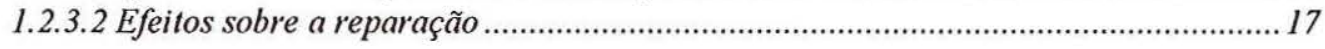

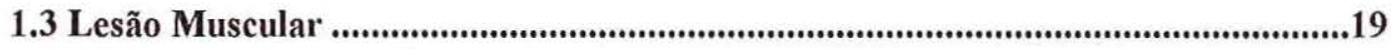

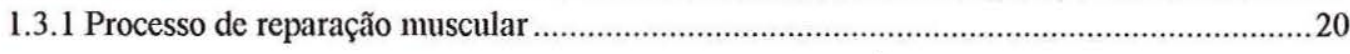

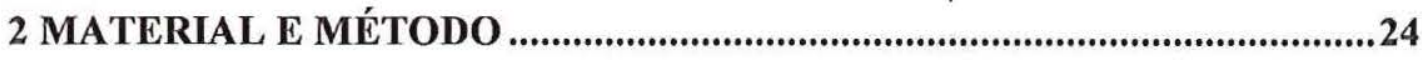

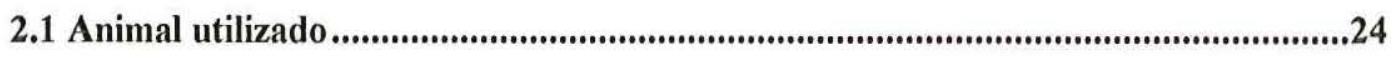

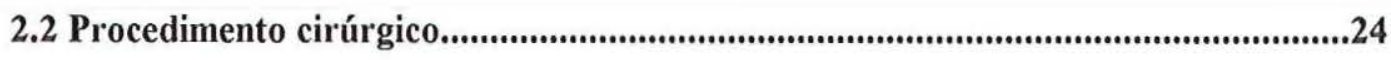

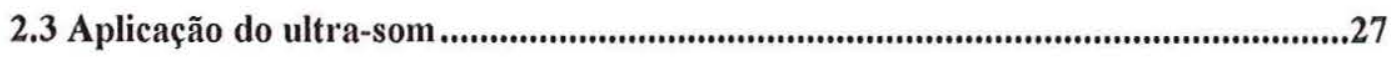

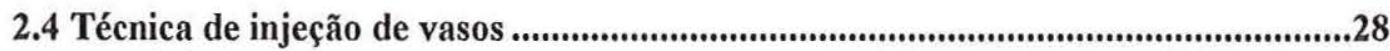

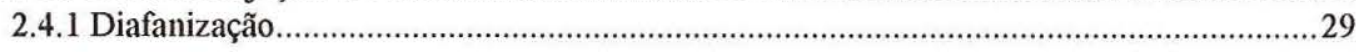

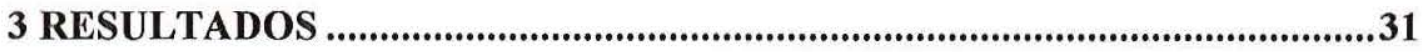

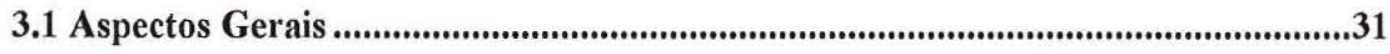

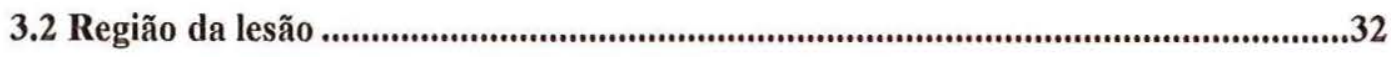

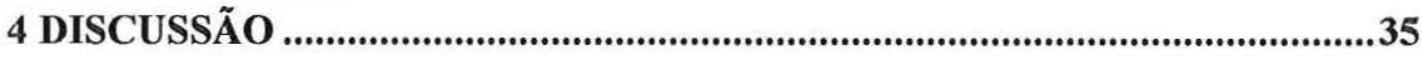

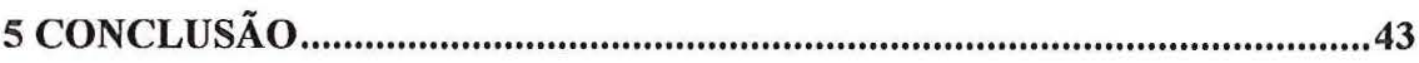

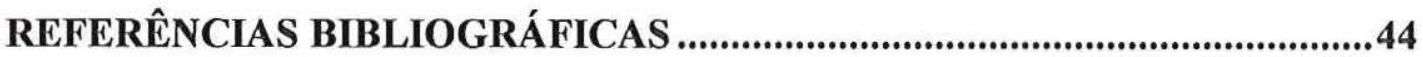

1. Normas de acordo com as Diretrizes para Elaboração de Dissertações e Teses na EESC-USP $2^{\mathrm{a}}$ ed. 


\section{LISTA DE FIGURAS}

FIGURA 1. PROPAGAÇÃO DA ONDA ULTRA-SÔNICA LONGITUDINAL ........................... 4

FIGURA 2. APRESENTAÇÃo dO SINAL PULSADO SINAL SENOIDAL PULSADO...............9

FIGURA 3. PASSOS DO PROCEDIMENTO CIRÚRGICO................................................26

FIGURA 4. VISUALIZAÇÃO DO QUADRÍCEPS APÓS RESSECADO DO FÊMUR..................30

FIGURA 5. MÚSCULO SUBMETIDO À INJEÇÃO DE VASOS, PANORÂMICA E DETALHE. 33 FIGURA 6. REGIÃO DA LESÃo APÓS INJEÇÃO DE VASOS, NO DETALHE 34 


\section{LISTA DE ABREVIATURAS E SIGLAS}

DNA - Ácido Desoxirribonucleíco

EESC - Escola de Engenharia de São Carlos

FMRP - Faculdade de Medicina de Ribeirão Preto

IQSC - Instituto de Química de São Carlos

SATA - Spacial Average and Temporal Average

USP - Universidade de São Paulo 


\section{LISTA DE SÍMBOLOS}

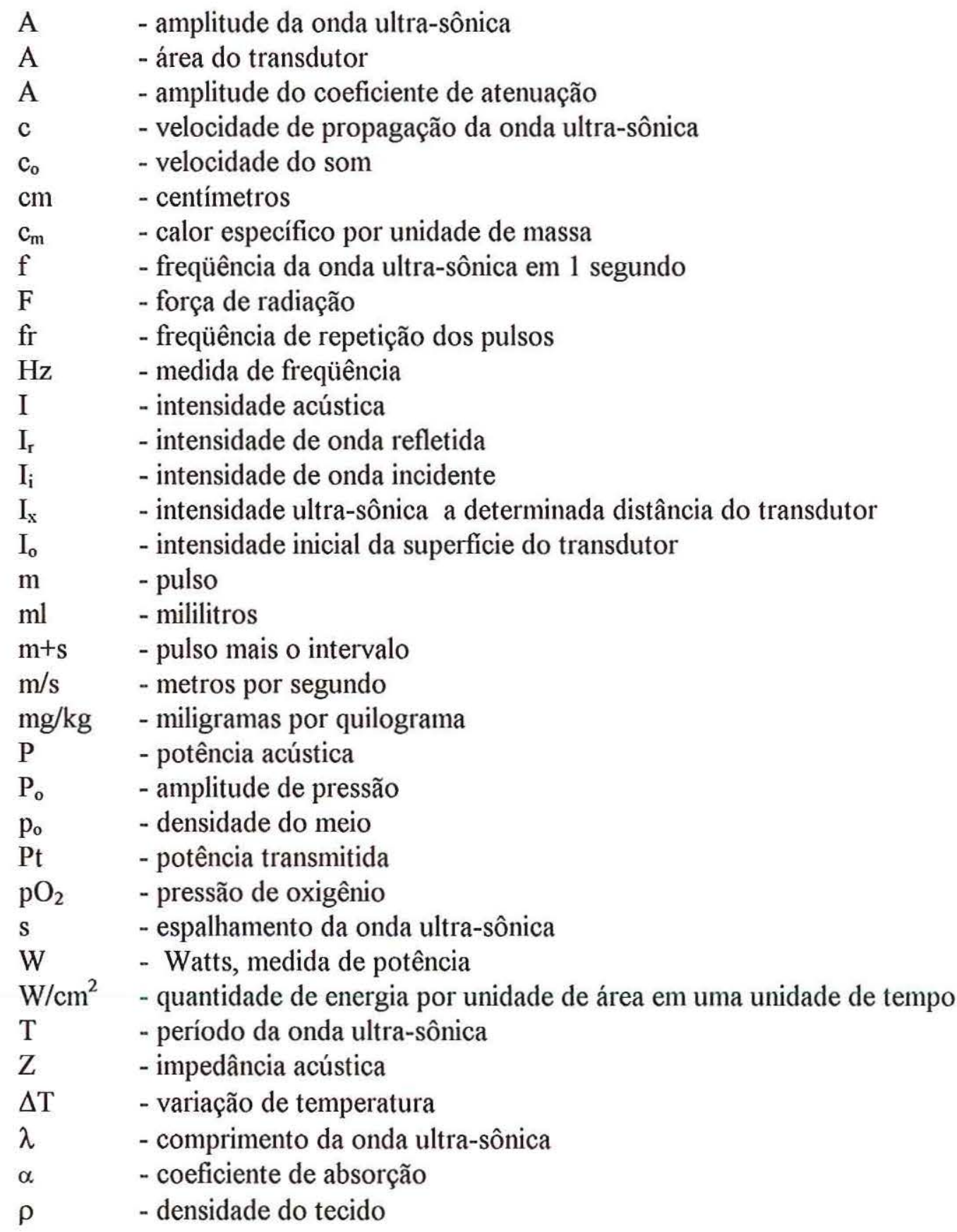




\section{RESUMO}

DIONÍSIO, V. C. (1998). O efeito do ultra-som terapêutico na vascularização pós lesão muscular experimental em coelhos. Ribeirão Preto, 1998. 47p. Dissertação (Mestrado) - Escola de Engenharia de São Carlos / Faculdade de Medicina de Ribeirão Preto/Instituto de Química de São Carlos, Universidade de São Paulo.

Este estudo analisou o efeito do ultra-som terapêutico na vascularização pós lesão muscular experimental em coelhos. Foram utilizados 10 coelhos da raça Nova Zelândia, com peso médio de $2,5 \mathrm{~kg}$. Os animais foram submetidos à lesão por esmagamento do músculo reto femoral em ambas as coxas e, após 24 horas um dos lados foi tratado com ultra-som terapêtico e o outro serviu como controle. A freqüência utilizada foi de $1 \mathrm{MHz}$ e intensidade de $0,5 \mathrm{~W} / \mathrm{cm}^{2}$ por 5 minutos, durante 10 dias consecutivos. Após 48 horas do término do período de tratamento, os animais foram sacrificados. Foi feita a lavagem do sistema vascular com solução fisiológica, e depois, feita a injeção de uma solução de sulfato de bário e tinta da China. Os músculos foram ressecados do fềmur e submetidos ao processo de diafanização de acordo com a técnica de Spalteholz. Depois que as peças ficaram transparentes, foram examinadas por microscópio cirúrgico. Os resultados não mostraram diferenças no padrão da vascularização (artérias e arteríolas) entre os lados tratados e não tratados, sugerindo que o ultra-som terapêutico não provocou mudanças no padrão vascular após aplicação precoce em lesão muscular. 


\section{ABSTRACT}

DIONÍSIO, V. C. (1998). The effect therapeutic ultrasound in vasculature of experimental muscular lesions in rabbits. Ribeirão Preto, 1998. 47p. Dissertação (Mestrado) - Escola de Engenharia de São Carlos / Faculdade de Medicina de Ribeirão Preto/Instituto de Química de São Carlos, Universidade de São Paulo.

The effects of therapeutic pulsed ultrasound was investigated on experimental muscular lesions of rabbits. Ten white New Zealand rabbits weighing $2,5 \mathrm{~kg}$ were operated on and a crush injury of the rectus femoris of both hind limbs was performed. Twenty-four hours later therapeutic ultrasound was applied on one side and the other side was kept as a control. The following parameters were used: frequency $1 \mathrm{MHz}$, intensity $0,5 \mathrm{~W} / \mathrm{cm}^{2}$, treatment time 5 minutes and a whole of 10 sessions were completed. Two days after completion of the treatment the animals were killed and the arterial system of the hind limbs was injected with a mixture of barium sulphate and Indian ink. The quadriceps was harvested and processed according the Spalteholz technique. The vasculature of the specimens, specially in the local of the injury was studied. The results showed no difference in the vascular pattern between the treated and untreated sides. 


\section{INTRODUÇÃO}

A demonstração de que o ouvido humano é capaz de detectar o som, cuja freqüência de onda esteja entre $16 \mathrm{~Hz}$ e $20 \mathrm{KHz}$, aproximadamente, remonta ao século passado, mas somente no início deste século, mais precisamente na década de 20 , após a primeira guerra mundial, conseguiu-se gerar e detectar ondas sonoras acima do limiar do ouvido humano, caracterizando o ultra-som.

O primeiro passo foi a construção de sonares para localização de submarinos, depois, nas décadas de 30 e 40, ao perceber-se alterações no tecido biológico quando irradiados por ultra-som, devido à geração de calor, vários métodos foram desenvolvidos com a finalidade de adequar a geração de calor e, assim, o ultrasom foi introduzido como recurso terapêtico. O ultra-som também era utilizado na indústria na deteç̧ão de falhas e trincas em ligas metálicas, mesmo antes do uso com finalidades terapêuticas.

Desde então, o ultra-som tem sido usado intensamente na indústria e na medicina, seja no diagnóstico ou na terapêutica. Além dos efeitos térmicos do ultrasom, os não térmicos também mereceram ateņ̧ão e estudo. Foi descoberto que havia outras modificações benéficas na reparação do tecido biológico irradiado, que não eram decorrentes somente do aumento de temperatura. Dentre outros, a angiogênese 
é um dos efeitos que tem sido atribuído ao ultra-som, porém o assunto é pouco explorado e com literatura restrita.

As lesões musculares, por sua vez, embora tenham grande incidência, parecem ter tido pouca atenção por parte dos especialistas, sendo dado maior importância às lesões ósseas, articulares e ligamentares. Entretanto, nos últimos anos, com o crescimento das atividades fisica e desportiva, as lesões musculares tornaramse objeto de estudo, com a finalidade de buscar recuperação rápida, de qualidade e eficaz. A vascularização é de extrema importância na reparação muscular, pois por meio dela é que ocorre o suprimento energético e a chegada de elementos celulares ao local da lesão (CARLSON \& FAULKNER, 1983).

No tratamento das lesões musculares o ultra-som também é amplamente utilizado com bons resultados clínicos, associado a técnicas como crioterapia, terapia manual e outras. Entretanto, a utilização do ultra-som tem caráter um tanto empírico (GAM \& JOHANNSEN, 1995) e, em comparação à sua utilização, poucas pesquisas foram feitas e, ainda, com controles não confiáveis, tornando necessário mais investigações na aplicação deste recurso tão utilizado na área médica ( CLARKE \& STENNER, 1976; PARTRIDGE, 1987; DYSON, 1987; MAXWELL, 1992).

\subsection{Objetivo}

Diante do exposto, este trabalho teve por objetivo investigar o efeito do ultra-som terapêutico na reparação da lesão muscular experimental em coelhos, mediante análise da vascularização. 


\subsection{Ultra-som}

\subsubsection{Bases físicas do ultra-som}

O som pode ser definido fisicamente como uma perturbação mecânica que se desloca através de ondas em um meio material. Quando a freqüência destas ondas ultrapassa $20 \mathrm{KHz}$ elas são chamadas ultra-sônicas.

As vibrações ultra-sônicas são ondas mecânicas que transferem energia de um ponto a outro (Teer HAAR, 1987). A propagação ocorre pela perturbação do ponto de equilíbrio das partículas, e estas vibram em torno deste ponto (Teer HAAR, 1978).

As ondas podem ser do tipo transversal e longitudinal, sendo que nas transversais as partículas deslocam-se em direção perpendicular à propagação da onda e ocorrem em meios sólidos. As ondas longitudinais (compressivas) deslocam-se na direção da propagação (FIGURA 1), e podem ser produzidas nos meios sólidos, líquidos e gasosos (WILLIAMS, 1983).

Os tecidos biológicos são considerados meios fluidos, portanto, abordaremos neste trabalho, somente as ondas ultra-sônicas longitudinais.

\subsubsection{Características das ondas ultra-sônicas}

As ondas ultra-sônicas são caracterizadas pelo comprimento, amplitude, período e freqüência.

O comprimento de onda ( $\lambda$ ) é a distância em que um movimento ondulatório se repete, ou seja, a distância entre dois pontos onde as partículas encontram-se no mesmo estado de movimento em um dado instante de tempo (Teer HAAR, 1978). 
DIREÇÃO DA PROPAGAÇÃO

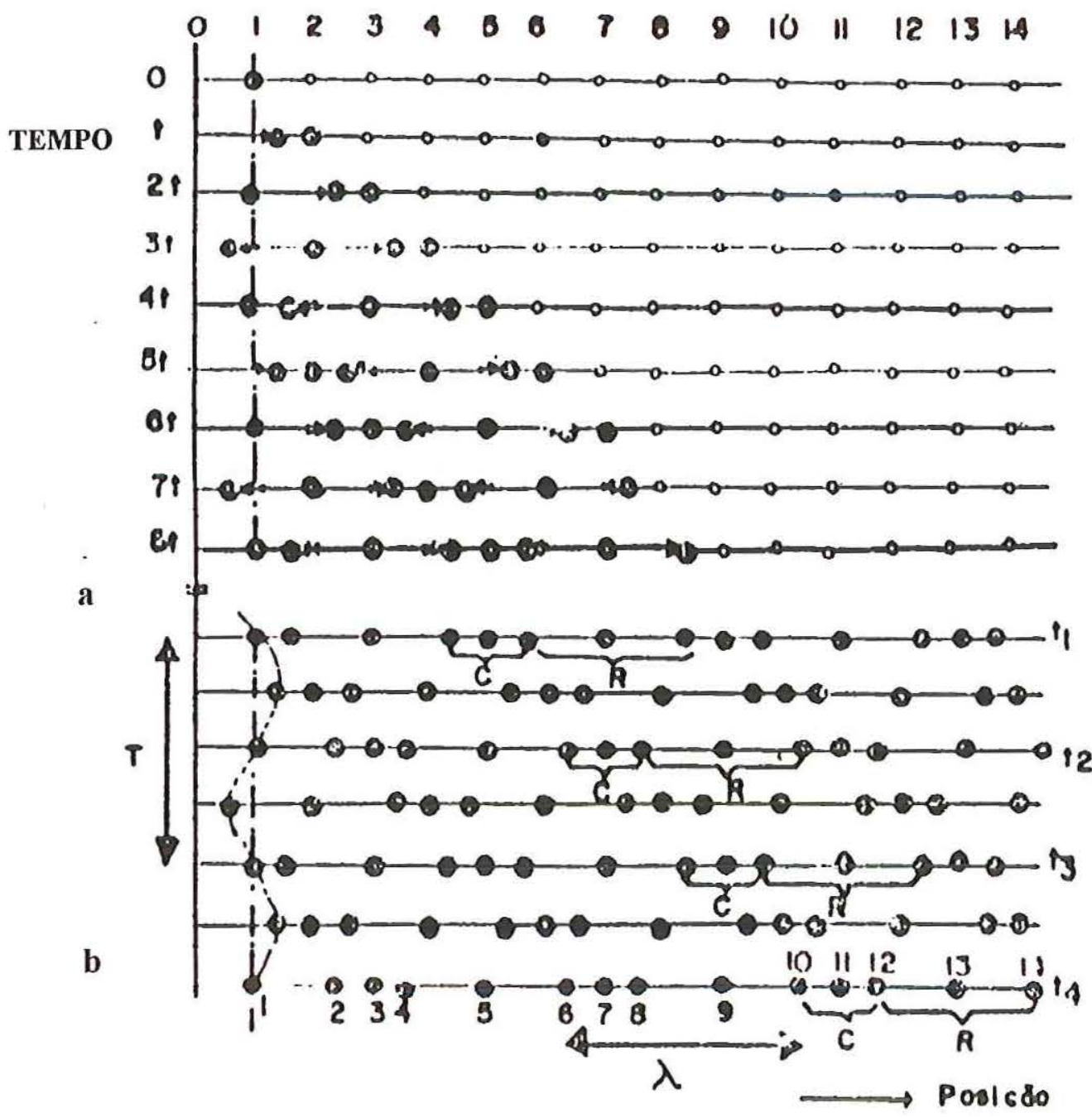

- PARTÍCULA EM MOVIMENTO C - COMPRESSÃo

- PARTÍCULA ESTACIONÁRIA R-RAREFAÇão

FIGURA 1. Diagrama da propagação de uma onda ultra-sônica longitudinal. A porção "a" do diagrama descreve o comportamento de uma única fileira de partículas, percorrida pela onda ultra-sônica ao longo do tempo. A cada intervalo de tempo considerado, a energia ultra-sônica atinge uma nova partícula. A porção " $b$ " do diagrama, mostra toda a fila em movimento, para diferentes instantes de tempo.

Fonte: Teer HAAR (1978). 
A amplitude ( A ) é a magnitude da perturbação da onda, dada pela distância máxima que uma partícula se desloca a partir de seu ponto de equilíbrio (Teer HAAR, 1987).

O período ( $\mathrm{T}$ ) é definido como o tempo necessário para que uma partícula realize um ciclo completo de movimento.

A freqüência ( $\mathrm{f}$ ) caracteriza-se pelo número de vezes que uma partícula realiza um ciclo oscilatório em uma unidade de tempo, considerado em 1 segundo.

A freqüência e o período são inversos, e relacionam-se pela equação:

$$
\mathrm{f}=\frac{1}{T}
$$

A velocidade ( c ) de propagação da onda é a distância percorrida por uma partícula em uma unidade de tempo. Desta forma, a velocidade tem relação com o comprimento da onda, a freqüência e o período, dada pela equação:

$$
\mathrm{c}=\frac{\lambda}{T}, \text { mas } \mathrm{f}=\frac{1}{T} \text {, então, } \mathrm{c}=\mathrm{f} \lambda
$$

A velocidade, ainda, pode ser influenciada pelo tipo de onda e a constante elástica do meio em que se propaga, sendo maior nos meios sólidos que nos líquidos e, estes, maiores que nos meios gasosos. Nos tecidos moles, a velocidade de propagação é da ordem de $1.500 \mathrm{~m} / \mathrm{s}$ (Teer HAAR, 1987).

\subsubsection{Produção e transmissão do ultra-som}

As ondas ultra-sônicas são geradas por meio de um transdutor, dispositivo que tem a capacidade de transformar um tipo de energia em outro (Teer HAAR, 1978). Estes transdutores convertem energia elétrica em energia mecânica e vice- 
versa, graças à capacidade piezoelétrica dos materiais de que são feitos (WILLIAMS, 1987).

O efeito piezoelétrico foi descrito por Pierre e Jacques Curie, em 1880, que observaram mudanças de cargas elétricas em certos cristais quando foram mecanicamente comprimidos (WILLIAMS, 1983). Inversamente, quando estimulados eletricamente, ocorre interação das cargas elétricas com estes materiais, produzindo tensões mecânicas (vibrações). Vários são os materiais com capacidades piezoelétricas que vão desde os naturais como o quartzo e turmalina até os produzidos artificialmente em laboratórios como o titanato de bário, cerâmicas e titanato zirconato de chumbo (Teer HAAR, 1978; WILLIAMS, 1983). Para ser usado como transdutor, o material deve ser conformado de maneira que ao se aplicar um campo elétrico alternado, produz-se variação de sua espessura, resultando em formação de ondas sonoras. A natureza da orientação do transdutor determina, também, que tipo de onda será produzida, que nas aplicações biológicas é a onda longitudinal, que se propaga nos sólidos e líquidos.

Para ocorrer a transmissão de ondas nos tecidos biológicos é necessário um meio acoplador, com a função de eliminar o ar entre o transdutor e o tecido, assegurando que a energia ultra-sônica chegue ao tecido alvo. Em geral, os meios mais utilizados são água, géis e alguns tipos de óleo (WILLIAMS, 1987).

\subsubsection{Campo ultra-sônico}

O transdutor possui a forma de um disco plano e sua superficie possui regiões diferentes entre si que agem como um transdutor, oscilando de forma 
independente. A interferência entre estas oscilações formam o campo ultra-sônico. O campo ultra-sônico pode ser dividido em 2 zonas distintas:

A zona de Fresnel (campo próximo), caracterizada pela ausência de divergência do feixe sônico e pelos fenômenos de interferência deste feixe, a intensidade é variada.

A zona de Fraunhofer (campo distante), caracterizada pela ausência total dos fenômenos de interferência, sendo o feixe sônico uniforme, divergente, de maior diâmetro e diminuição gradual da intensidade.

\subsubsection{Parâmetros do campo ultra-sônico}

Para que o campo ultra-sônico possa ser descrito no tempo e no espaço, é necessário estabelecer alguns parâmetros (Teer HAAR, 1987).

A intensidade ( I ) é definida como a quantidade de energia que cruza uma unidade de área em uma unidade de tempo, expressa em W/ $/ \mathrm{cm}^{2}$. A intensidade é dada pela expressão:

$$
\mathrm{I}=\frac{P_{o}^{2}}{2 p_{o} c_{o}} \quad \text { onde: }
$$

$\mathrm{P}_{\mathrm{o}}$ é a amplitude de pressão

$p_{o}$ é a densidade do meio

$\mathrm{c}_{\mathrm{o}}$ é a velocidade do som

Os valores de intensidade, que geralmente são descritos, são valores de intensidade média transmitidos pelo transdutor ultra-sônico, pela média temporal e média espacial ("Spacial Average and Temporal Average" - SATA), não sendo a 
intensidade "in situ", pois esta é dificil de ser medida, embora possa ser calculada teoricamente (KREMKAU, 1985).

A intensidade é mensurada por dosímetros em um meio de baixa atenuação, geralmente a água, que medem a força de radiação $(F)$, possibilitando calcular a potência acústica pela equação:

$$
\mathrm{F}=\frac{P}{c}
$$

A partir da potência acústica, pode-se calcular a intensidade acústica em média temporal e espacial (I), definida como o quociente entre a potência acústica transmitida $(\mathrm{Pt})$ e a área do transdutor $(\mathrm{A})$.

$$
\mathrm{I}=\frac{P t}{A}
$$

A potência é a energia total transmitida pelo feixe ultra-sônico, medida em Watts (W) e serve de interesse para o planejamento e construção de aparelhos.

A proporção espacial é a proporção da largura dos pulsos pela duração do intervalo entre eles, usada nos aparelhos de ultra-som pulsado.

A taxa de repetição, também usada nos aparelhos de ultra-som pulsado é definida como repetição do pulso $(\mathrm{m})$ pelo pulso mais o intervalo $(\mathrm{m}+\mathrm{s})$. É dada em porcentual:

$$
\frac{m}{m+s} \times 10
$$

O tempo de irradiação pode ser calculado, desde que se tenha a taxa de repetição ou a proporção espacial no caso do ultra-som pulsado. Na utilização terapêutica estes conceitos são muito importantes, pois a intensidade do campo ultra- 
sônico pode ter picos muito altos e a média espacial de intensidade ser baixa (Teer HAAR, 1987).

\subsubsection{Modos de produção}

O ultra-som pode ser produzido na forma de ondas contínuas ou pulsadas, sendo que a diferença entre elas está na interrupção ou não da propagação de energia (FIGURA 2). No modo contínuo, não ocorre interrupção havendo, portanto, transferência contínua de energia para o tecido irradiado. No modo pulsado há interrupções constantes da propagação de energia. Assim, dois tipos de freqüência são considerados: a freqüência da onda (f) já citada, e a freqüência de repetição dos pulsos (fr).

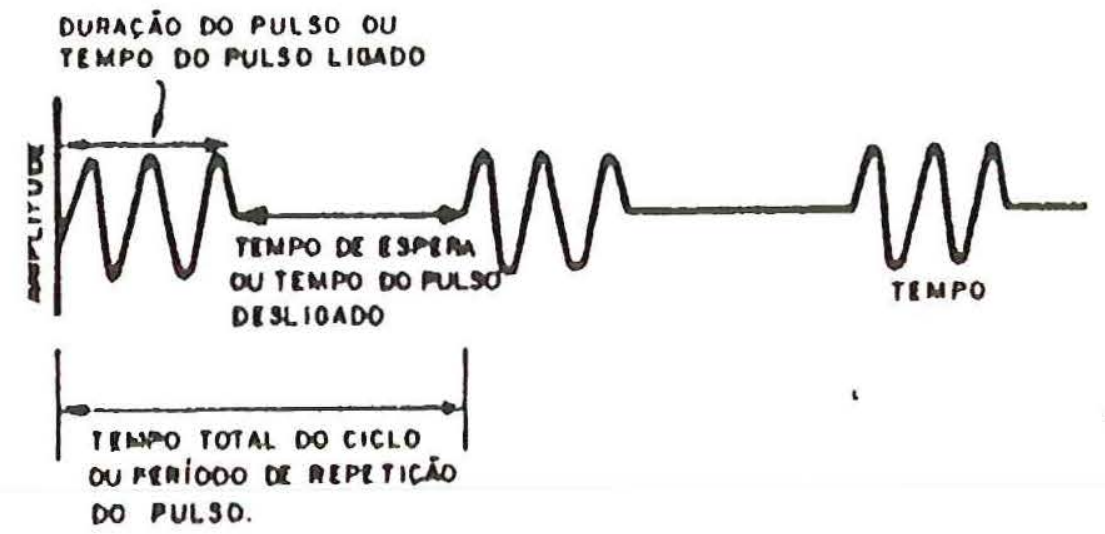

FIGURA 2. Sinal senoidal pulsado, onde o tempo total do ciclo é composto pela duração do pulso ligado e tempo de pulso desligado. Fonte: KREMKAU (1985)

\subsubsection{Refração e reflexão}

A refração e reflexão são propriedades das ondas quando encontram uma interface de meios diferentes, sendo parte delas refletida e parte refratada. A parte 
refletida retorna ao meio incidente com a mesma velocidade de propagação. No entanto, a parte refratada continua em direção positiva, mas sua velocidade altera-se dependendo das características do meio (WILLIAMS, 1983).

\subsubsection{Impedância acústica}

Impedância acústica $(Z)$ é definida como um número obtido pela multiplicação da densidade de um material e a velocidade na qual o som o atravessa. Quando a impedância acústica é igual entre dois meios, nenhuma onda será refletida, mas quanto maior a diferença entre as impedâncias, maior será a energia refletida (WILLIAMS, 1987). Em uma incidência normal isto é expresso matematicamente como:

$$
\frac{I_{r}}{I_{i}}=\left[\frac{Z_{2}-Z_{1}}{Z_{2}+Z_{1}}\right]^{2} \quad \text { onde: }
$$

$\mathrm{I}_{\mathrm{r}}$ é intensidade de onda refletida

$\mathrm{I}_{\mathrm{i}}$ é intensidade de onda incidente

$Z_{1}$ é a impedância acústica do meio 1

$Z_{2}$ é a impedância acústica do meio 2 (do outro lado da interface)

\subsubsection{Atemuação}

Atenuação é o fenômeno de perda de energia quando a propagação ocorre em um meio não homogêneo, provocando decréscimo na intensidade, à medida que a 
distância do transdutor aumenta. Este processo ocorre devido ao espalhamento da onda e à absorção de energia. Nos tecidos biológicos as diferenças entre vasos sangüíneos, células, fibras, tecido conjuntivo causam espalhamento. Contudo, a absorção de energia ocorre e pode ser mensurada pelo aumento da temperatura. Sua representação matemática é dada como:

$$
I_{x}=I_{0} e^{-2 A x} \quad \text { onde: }
$$

$\mathrm{I}_{\mathrm{x}}$ é a intensidade ultra-sônica a uma distância $\mathrm{x}$ do transdutor

$I_{0}$ é a intensidade inicial da superficie do transdutor

A é a amplitude do coeficiente de atenuação, sendo composta pelo coeficiente de absorção ( $\alpha$ ) e o de espalhamento (s), (WILLIAMS, 1983).

O coeficiente de absorção $(\alpha)$ é diretamente proporcional à freqüência. Assim, quanto maior for a freqüência, maior será a produção de calor. Por esta razão as freqüências são limitadas quando o uso é terapêutico.

\subsubsection{Mecanismos de interação do ultra-som e tecidos biológicos}

Na interação do ultra-som e tecidos biológicos, ocorre a formação de um campo de perturbações mecânicas, com efeitos biológicos associados. Estes efeitos são classificados como térmicos e não térmicos ( mecânicos ).

\subsubsection{Efeitos térmicos}

A absorção da energia mecânica da onda ultra-sônica pelo tecido é transformada em calor (Teer HAAR, 1987; WILLIAMS, 1983; LEHMANN, 1953). Este calor tecidual depende de uma série de fatores tais como o coeficiente de 
absorção, a taxa de energia ultra-sônica depositada (dependente da intensidade e modo de propagação), a freqüência da onda, o tempo de irradiação, dimensões do corpo aquecido e a presença ou ausência de reflexão na frente ou atrás do tecido alvo (WILLIAMS, 1983).

Teer HAAR (1987) afirmou ser possível estimar a ordem de aumento de temperatura $(\Delta \mathrm{T})$ que pode ser esperada após irradiação com uma intensidade I e tempo $t$, dada por:

$$
\Delta \mathrm{T}=\frac{2 \alpha_{a} I t}{\rho c_{m}} \quad \text { onde: }
$$

$\alpha_{a}$ é o coeficiente de absorção

$\rho$ é a densidade do tecido

$\mathrm{c}_{m}$ é o calor específico por unidade de massa para o tecido

A temperatura tecidual precisa ser mantida entre 40 e $45^{\circ} \mathrm{C}$, pelo menos por 5 minutos e, assim, alcançar efeitos terapêuticos pelo aquecimento, dentre os quais aumento da elasticidade de estruturas altamente colagenosas, diminuição da rigidez articular, dor, espasmo muscular, sendo o aumento de temperatura dependente do fluxo sangüíneo e do tipo do tecido (DYSON, 1987). No entanto, o mecanismo térmico não é o único, pois movimentando o transdutor, o valor da temperatura será menor (Teer HAAR, 1987) e variações do comprimento de pulso e intensidade de pulso produzem muitos efeitos (DYSON \& SUCKLING, 1978) com temperaturas baixas, sugerindo que outros mecanismos não térmicos participem da ação biológica do ultra-som (DYSON, 1987). 


\subsubsection{Efeitos não térmicos}

Em várias situações onde o sistema é resfriado ou as intensidades são pequenas, tem-se observado que o aumento de temperatura é baixo e desprezível, mostrando que outros mecanismos que não o aquecimento provocam modificações no tecido biológico. Alguns autores têm relatado estes efeitos (DYSON; POND; JOSEPH, 1970; DYSON \& SUCKLING, 1978; ROCHE \& WEST, 1984; YOUNG \& DYSON, 1990a, YOUNG \& DYSON, 1990b), dentre os quais citamos o aumento da permeabilidade celular, aumento da síntese protéica, aumento do fluxo de íons cálcio e metabólitos através da membrana celular afetando de forma positiva a reparação tecidual. Os mecanismos considerados não térmicos são o fluxo acústico, pressão de radiação, força de radiação, torque de radiação e cavitação.

O fluxo ou corrente acústica significa uma constante circulação de fluidos induzida pela força de radiação (DYSON, 1987). Quando esta corrente envolve pequenas estruturas como células e os movimentos são de proporções microscópicas, usa-se o termo microfluxo.

É este fluxo acústico que promove os efeitos não térmicos favoráveis do ultra-som como mudanças da permeabilidade celular, secreção de agentes quimiotáticos, difusão de metabólitos e cálcio através da membrana celular e alteração de mobilidade de fibroblastos e células endoteliais (DYSON, 1987).

O termo cavitação é usado para caracterizar a formação de cavidades ou bolhas no meio líquido. Estas bolhas podem ser dirigidas pelo campo ultra-sônico e oscilar em uma faixa estável, aumentando e diminuindo o volume pela variação de pressão do campo, determinando uma cavitação estável. Quando ocorre oscilação de 
uma maneira violenta, fazendo largas excursões no volume provocando completo colapso, ocorre uma cavitação transitória (Teer HAAR, 1987).

A cavitação estável tem sido considerada como terapêutica e até necessária para que algumas modificações ocorram (DYSON, 1987; YOUNG \& DYSON, 1990a).

A cavitação transitória, por sua vez, é prejudicial pela alteração de pressão e altas temperaturas na região da bolha colapsada, lesando tecidos com formação de radicais livres (DYSON, 1987) e hemorragias petequiais (LEHMANN, 1953).

\subsubsection{Aplicação terapêutica do ultra-som}

A aplicação terapêutica do ultra-som, ao longo dos anos, justificou-se por mudanças nos tecidos biológicos, mais precisamente na resolução do processo inflamatório e conseqüente reparação da lesão. Podemos dividir a aplicação terapêutica nos efeitos sobre a temperatura, na circulação e nos efeitos sobre a reparação.

\subsubsection{Efeitos sobre a temperatura e circulação}

LEHMANN (1953) estudou a ação do ultra-som terapêutico nos tecidos biológicos às exposições de 1,5 a $3,1 \mathrm{~W} / \mathrm{cm}^{2}$ e observou reações como hiperemia (reação suave), combinada com edema (reação média) e necrose (reação grave). Todas reações foram dependentes da temperatura, sendo que, quando o tecido era resfriado durante a exposição ultra-sônica, nenhuma reação era observada. Estes resultados sugeriram que os efeitos sobre o tecido biológico são dependentes do 
aumento de temperatura. Diferentemente, as investigações sobre a temperatura da pele de PAASKE; HOVIND; SEJRSEN (1973) que utilizaram ultra-som contínuo e pulsado por 3 minutos, com intensidade de $0,25 \mathrm{~W} / \mathrm{cm}^{2}, 0,5 \mathrm{~W} / \mathrm{cm}^{2}$ e $0,75 \mathrm{~W} / \mathrm{cm}^{2}$ e no tecido muscular, utilizaram ultra-som contínuo a $1,5 \mathrm{~W} / \mathrm{cm}^{2}$ de intensidade, por 2 minutos, apontaram para não correlação entre dose e fluxo sangüíneo ou mudanças de temperatura na pele. No tecido subcutâneo e muscular, as mudanças encontradas do fluxo sangüíneo foram insignificantes. DRAPER; CASTEL; CASTEL (1995) por sua vez, compararam a taxa de aumento de temperatura no músculo de seres humanos. Na região medial do tríceps sural foram determinadas duas profundidades para cada freqüência, sendo 2,5 e 5,0 $\mathrm{cm}$ para $1 \mathrm{MHz}$ e 0,8 e 1,6 cm para $3 \mathrm{MHz}$. As doses foram de $0,5 \mathrm{~W} / \mathrm{cm}^{2}, 1,0 \mathrm{~W} / \mathrm{cm}^{2}, 1,5 \mathrm{~W} / \mathrm{cm}^{2}$ e $2,0 \mathrm{~W} / \mathrm{cm}^{2}$ por 10 minutos cada tratamento e a temperatura mensurada a cada 30 segundos por meio de termômetros. Não foram encontradas diferenças significantes nas duas profundidades em todos níveis de dose, porém, a freqüência de $3 \mathrm{MHz}$ aqueceu mais rapidamente que a freqüência de $1 \mathrm{MHz}$.

Estes trabalhos mostram que o aumento de temperatura não está sempre presente e, que os possíveis efeitos do ultra-som não são totalmente dependentes da variação da temperatura, devendo haver outros mecanismos de atuação. Independente da temperatura, o ultra-som parece ter efeitos sobre a circulação, como estudado por DYSON \& POND (1973), que investigaram a influência do ultra-som sobre a circulação de embriões de galinha, observados microscopicamente. Verificaram que houve estase de células sangüíneas que se agrupavam em bandas espaçadas e, de maneira angular, de acordo com a propagação da onda. Também foram encontrados

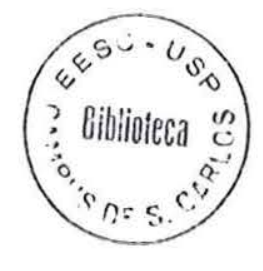


danos endoteliais. Estas alterações, no entanto, podem ser prevenidas movimentando o transdutor e o uso de uma intensidade limiar de $0,5 \mathrm{~W} / \mathrm{cm}^{2}$.

A possibilidade do ultra-som aumentar o fluxo sangüíneo em tecidos isquêmicos foi estudada por HOGAN; BURKE; FRANKLIN (1982) que usaram músculos cremaster de ratos, expostos a uma freqüência de $1 \mathrm{MHz}$ no modo pulsado, com intensidade de 1,25 a $10,0 \mathrm{~W} / \mathrm{cm}^{2}$ e com um tempo de 5 minutos em dias alternados, por 1 ou 3 semanas. Os achados mostraram diferença significante entre estimulação aguda e crônica do músculo, onde as arteríolas constringiam-se imediatamente, mas a repetição da exposição a $2,5 \mathrm{~W} / \mathrm{cm}^{2}$ melhorou o fluxo sangüíneo.

RUBIN et al. (1990) examinaram os efeitos agudos do ultra-som pulsado na microvascularização do músculo cremaster de rato, mensurando o fluxo sangüíneo do tecido, densidade capilar e pressão de oxigênio. Foram realizadas exposições com 2,5 e 5,0 W/cm², com freqüência de $1 \mathrm{MHz}$, e verificaram que com $2,5 \mathrm{~W} / \mathrm{cm}^{2}$ não houve diferença significativa no fluxo sangüíneo e na densidade capilar. Entretanto, a tensão de oxigênio foi reduzida no tecido normal. A densidade capilar foi significantemente diminuída no tecido isquêmico após exposição a $5 \mathrm{~W} / \mathrm{cm}^{2}$. O fluxo de sangue diminuiu somente no tecido normoxigenado. Por estes dados os autores sugeriram que o ultra-som, em intensidade e freqüências empregadas, foi capaz de produzir uma redução mínima no $\mathrm{pO}_{2}$ tecidual, durante o período de recuperação após exposição, podendo desempenhar função na melhora da resposta de reparação. Entretanto, a observação do fluxo sangüíneo na pele de sujeitos normais, ROBINSON \& BUONO (1995) não encontraram diferenças significativas entre o lado tratado e controle (placebo), sugerindo que a administração da onda sônica contínua na freqüência de 
$1 \mathrm{MHz}$ e intensidade de $1,5 \mathrm{~W} / \mathrm{cm}^{2}$, por 5 minutos, não tem efeito sobre o fluxo sangüíneo, indicando que este não é o mecanismo primário dos achados observados após o uso do ultra-som.

\subsubsection{Efeitos sobre a reparação}

Os trabalhos referentes à reparação propriamente dita proporcionaram maior conhecimento sobre os efeitos do ultra-som e sua forma de atuação. DYSON; POND; JOSEPH (1970) utilizaram ultra-som pulsado 14 dias após a produção de lesões cutâneas em orelhas de coelhos. Usaram freqüência de $3,5 \mathrm{MHz}$ e intensidade entre $0,1 \mathrm{e} 0,8 \mathrm{~W} / \mathrm{cm}^{2}$, por 5 minutos. Foram observados, no lado experimental, aumento da síntese de DNA e presença de muitos fibroblastos produzindo colágeno, diferentemente do lado controle. Estes achados não tiveram relação com a temperatura, sugerindo que o efeito mais importante foi o mecânico. Resultados semelhantes também foram encontrados por POSPISILOVÁ (1976) ao investigar a ação do ultra-som na síntese de colágeno e deposição de granuloma em ratos. Os animais foram expostos às freqüências de $0,8 \mathrm{MHz}$ e intensidade de $1,0 \mathrm{~W} / \mathrm{cm}^{2}$ por 5 minutos, na fase aguda (2 a 21 dias) e crônica (16 a 35 dias). DYSON; FRANKS; SUCKLING (1976) trataram úlceras varicosas com a utilização de ultra-som, na freqüência de $3 \mathrm{MHz}$ em regime pulsátil de 2:8 $\mathrm{ms}$ a uma intensidade de $1,0 \mathrm{~W} / \mathrm{cm}^{2}$ por 5 minutos. Houve diferença significante entre os grupos controle e tratado, porém o mecanismo pelo qual o ultra-som atuou foi incerto.

DYSON \& SUCKLING (1978) discutiram os possíveis mecanismos envolvidos na reparação de úlceras varicosas. Os autores apontam os efeitos não 
térmicos, os responsáveis por induzir mudanças de valores de difusão e permeabilidade celular e organelas, que podem alterar a síntese de proteínas e estimular a reparação. Observações semelhantes foram feitas por ROCHE \& WEST (1984) ao utilizarem o ultra-som em úlceras varicosas. Os efeitos favoráveis à reparação, foram atribuídos às alterações induzidas na membrana celular pelo microfluxo e cavitação estável. A alteração da permeabilidade aos íons sódio e o aumento temporário no cálcio intracelular, aumentaram a síntese de proteínas, produção de histaminas por macrófagos, além de estimularem miofibroblastos diferenciados. A aceleração do processo de reparação do ultra-som também foi observada por ENWEMEKA (1989) ao avaliar mecanicamente tendões de Aquiles tenotomizados e tratados com ultra-som. Foi utilizada a freqüência de $1 \mathrm{MHz}$ no modo contínuo e intensidade de $1 \mathrm{~W} / \mathrm{cm}^{2}$, em 9 sessões. A capacidade de absorção de energia foi maior nos coelhos tratados, sugerindo aceleração do processo de reparação.

Para compreender melhor estes efeitos do ultra-som YOUNG \& DYSON (1990b) estudaram se o ultra-som podia estimular fatores mitogênicos de fibroblastos em macrófagos "in vitro". Foram usadas as freqüências de 0,75 e $3,0 \mathrm{MHz}$ por 5 minutos, com intensidade de $0,5 \mathrm{~W} / \mathrm{cm}^{2}$. Após 5 dias foi observado que na freqüência de $0,75 \mathrm{MHz}$ pareceu ser efetiva na liberação de substâncias afetando a proliferação de fibroblastos, provocadas por alterações no comportamento celular em relação aos śns cólcio Os resultados mostraram que o ultra-som pode estimular a liberação de O aumento da neoformação de vasos, encontrado por YOUNG \& DYSON (1990a) após 5 dias de lesão cutânea da pele de rato, avaliados por 
microdensitometria e análise de imagem, foi explicado pela capacidade do ultra-som em provocar a desgranulação dos macrófagos e, assim, ocorrer a liberação de fatores angiogênicos e fatores de crescimento de fibroblastos sendo, portanto, indicado seu uso na fase aguda da reparação da pele.

O tecido muscular, parece ter resposta semelhante, como constatou MENEZES (1997) ao tratar com ultra-som pulsado na fase aguda (10 primeiros dias), lesão muscular em reto femoral de coelhos e, analisar as propriedades mecânicas. Os resultados mostraram que os músculos tratados apresentaram maior deformação máxima e maior carga e deformação no limite de proporcionalidade, sugerindo que o ultra-som beneficiou o processo de reparação.

\subsection{Lesão Muscular}

Considerando-se as lesões do aparelho locomotor, as musculares estão entre as mais comuns, nas pessoas sedentárias, atletas ocasionais e especialmente em atletas de competição, estejam eles em esportes individuais ou coletivos. As lesões ocorrem por isquemia, doenças que afetam o tecido muscular (miopatias) e por traumatismos, que podem ser diretos ou indiretos (esforço).

O estudo e classificação das lesões musculares traumáticas tem apresentado algumas divergências, sobretudo na classificação das lesões. LEHTO \& JÄRVINEN (1991) classificaram as lesões em contusão, lesões por esforço e laceração muscular, podendo ser de grau leve, moderado ou grave. Em contrapartida, LOPES et al. (1993) classificaram as lesões baseados em estudos clínicos e ressonância magnética como contusão (causa extrínseca), cãibras, contratura e estiramento (causa intrínseca 
e sem roturas), e lesões com roturas podendo ser parcial ou total. CARAZZATO (1994) classificou as lesões em ferida, necrose, contusão e ruptura (parcial e total), dispensando o uso do termo contratura, pois ele significa estado do músculo em contração no momento da lesão sendo, portanto, considerado pelo autor um termo inadequado.

Independentemente da classificação, o fato é que com a alta incidência da lesão, o crescimento e valorização da Medicina do Esporte e da Fisioterapia, os músculos têm recebido maior atenção, surgindo a necessidade de uma recuperação rápida, com qualidade, aproveitando o potencial regenerativo que as fibras musculares possuem. Isto tem estimulado pesquisadores na compreensão das causas das lesões musculares, bem como as alterações no tecido muscular quando em reparação e, conseqüentemente, administração de um tratamento mais adequado.

\subsubsection{Processo de reparação muscular}

O processo de reparação muscular tem sido descrito desde o final do século passado, mas somente nos últimos trinta anos foi realmente estabelecida a capacidade de regeneração das fibras musculares esqueléticas (CARLSON \& FAULKNER, 1983).

Após uma lesão, ocorrem várias modificações estruturais na região traumatizada, com uma seqüência de eventos que tem sido descrita em vários trabalhos (ALLBROOK, 1962; CARLSON \& FAULKNER, 1983; NIKOLAOU et al., 1987; FISHER et al., 1990; LEHTO \& JÄRVINEN, 1991; HURME et al., 1991; RANTANEN et al., 1995). 
A regeneração muscular em mamíferos destaca-se pelo aproveitamento do que restou das fibras musculares originais, sendo dividida em regeneração contínua e descontínua. A regeneração contínua ocorre pelo brotamento ou crescimento para fora da fibra parcialmente lesada, diferentemente da regeneração descontínua, onde a fibra muscular é destruída e uma nova fibra é formada pelas células mioblásticas (CARLSON \& FAULKNER, 1983).

A regeneração descontínua tem sido mais estudada, e seu evento inicial consiste em degeneração intrínseca da própria fibra muscular, com presença de hematoma e edema (ALLBROOK, 1962; CARLSON \& FAULKNER, 1983; HURME et al., 1991; CRISCO et al., 1994), sendo observada entre 6 e 24 horas após a lesão (NIKOLAOU et al., 1987; FISHER et al., 1990). Seguindo a degeneração, células satélites localizadas abaixo da lâmina basal são ativadas (CARLSON \& FAULKNER, 1983; LEHTO \& JÄRVINEN, 1991) 24 horas (FISHER et al., 1990) e 48 horas após a lesão (HURME et al., 1991; CRISCO et al., 1994).

Juntamente com a ativação das células satélites, uma intensa reação inflamatória desenvolve-se, com predomínio dos macrófagos, leucócitos polimorfonucleares e outras células com a finalidade de fagocitar elementos necróticos dentro do cilindros de lâmina basal (ALLBROOK, 1962; CARLSON \& FAULKNER, 1983; NIKOLAOU et al., 1987; LEHTO \& JÄRVINEN, 1991), sendo observáveis de 6 horas (FISHER et al., 1990) a 24 horas após a lesão (HURME et al., 1991; CRISCO et al., 1994). A ativação de fibroblastos também ocorre, podendo ser encontrada desde 24 horas após lesão, mas é após 36 horas que se observa a formação de fibrose local intersticial (FISHER et al., 1990), e colágeno do tipo IV (HURME et al., 1991). ALLBROOK (1962) sugeriu que a justaposição em que os 
fibroblastos se encontram precocemente no processo de reparação mostra que o colágeno tem o importante papel de limitar o crescimento das fibras musculares.

As células satélites ativadas são transformadas em mioblastos, fundem-se dentro dos miotubos multinucleados e começam a produzir proteínas musculares específicas, diferenciando-se em fibras maduras e deslocando o núcleo para a periferia (LEHTO \& JÄRVINEN, 1991). No entanto, RANTANEN et al. (1995) observaram o primeiro sinal de diferenciação miogênica entre 4 e 8 horas após lesão, sendo que proliferação foi vista somente após 24 horas, sugerindo que existem duas populações de células precursoras: as que estão prontas para diferenciação imediata e as que sofrem mitoses, proliferação e diferenciação.

HURME et al. (1991) observaram que, em torno do $5^{\circ}$ dia após lesão, somente macrófagos permanecem na região, os cilindros de lâmina basal estão cheios de células musculares, com matriz de tecido conjuntivo mais densa. Em torno do $7^{\circ}$ dia foram encontrados fibroblastos ativos paralelos às miofibrilas secretando colágeno. Estes achados foram, também, encontrados nos trabalhos de NIKOLAOU et al. (1987), FISHER et al. (1990) e CRISCO et al. (1994). Por volta do $14^{\circ}$ dia, os achados foram semelhantes acrescentando-se que o colágeno foi depositado em fibras musculares regeneradas e nas preservadas (HURME et al., 1991).

Em todo este processo de reparação é importante ressaltar o papel da lâmina basal preservada da fibra muscular original, servindo como um ancoradouro para reconstrução da fibra muscular, promovendo um ambiente favorável à regeneração e ainda mantendo fibroblastos e novas formações de colágeno excluídas do ambiente, evitando interferências no crescimento da nova fibra muscular. (CARLSON \& FAULKNER, 1983; LEHTO \& JÄRVINEN, 1991). 
O processo de reparação também é altamente dependente da vascularização da área lesada, como observou JÓZSA et al. (1980) ao avaliar tensões de oxigênio e dióxido de carbono nas lesões por esmagamento em ratos. A maior intensidade de crescimento capilar ocorreu no $3^{\circ}$ dia após o trauma e, após 1 semana, os capilares invadiram o centro da lesão, normalizando o suprimento de oxigênio no $10^{\circ}$ dia. A reparação total caracterizou-se pelo excesso de tensão de oxigênio entre o $14^{\circ}$ e $18^{\circ}$ dia após a lesão. LEHTO \& JÄRVINEN (1991) reforçaram esta relação de dependência, sugerindo que o processo de reparação é dependente do meio ambiente metabólico e que há indicações dele ser aeróbio e manter uma relação íntima com a vascularização. 


\section{MATERIAL E MÉTODO}

\subsection{Animal utilizado}

Foram utilizados 10 coelhos albinos, da raça Nova Zelândia, fêmeas, com peso corporal em torno de $2,5 \mathrm{~kg}$, fornecidos pelo Biotério Central da Faculdade de Medicina de Ribeirão Preto da Universidade de São Paulo. Os animais foram operados e, depois, mantidos no Biotério do Laboratório de Bioengenharia da Faculdade de Medicina de Ribeirão Preto da Universidade de São Paulo, sem restrição de alimentação padrão (ração) e água.

Antes da realização do procedimento cirúrgico os animais foram pesados e identificados com marcas nas orelhas.

\subsection{Procedimento cirúrgico}

O procedimento cirúrgico para produção da lesão muscular foi realizado no Laboratório de Bioengenharia da Faculdade de Medicina de Ribeirão Preto da Universidade de São Paulo. O modelo de lesão muscular utilizado foi o de ALLBROOK (1962), com algumas modificações.

Os animais foram anestesiados com pentobarbital sódico, aplicado endovenosamente, na dose inicial de $40 \mathrm{mg} / \mathrm{kg}$ de peso corporal. Doses adicionais foram administradas conforme a necessidade, para manutenção do plano anestésico. 
Inicialmente, ambas coxas foram tricotomizadas. A cirurgia foi realizada em ambiente cirúrgico, com uso de campos isolantes e material cirúrgico rotineiro, esterilizados.

Os principais passos técnicos foram:

1- Posicionamento do animal em decúbito lateral, com os joelhos fixados em $90^{\circ}$ de flexão,

2- Anti-sepsia da pele com álcool iodado $4 \%$ e colocação de campos fenestrados,

3- Incisão cutânea, retilínea, na face externa do terço médio da coxa de mais ou menos $2,5 \mathrm{~cm}$ de comprimento,

4- Afastamento da pele e visualização da massa muscular do quadríceps. Identificação do septo intermuscular entre o músculo vasto lateral e reto femoral (FIGURA 3a),

5- Divulsão muscular pelo septo de modo a separar os dois músculos até a face medial da coxa (FIGURA 3b),

6- Com régua metálica milimetrada, foi determinada uma distância de $3,0 \mathrm{~cm}$ do pólo proximal da patela até o reto femoral,

7- Nesta localização foi introduzida uma pinça hemostática tipo "Kelly" de modo que o músculo reto femoral ficasse preso entre suas extremidades. Sempre foi usada a mesma pinça e o limite de introdução foi padronizado e controlado por uma marca na própria pinça (FIGURA 3c),

8- Com o posicionamento adequado da pinça hemostática, ela foi fechada até o primeiro dente da cremalheira, de modo a esmagar o músculo durante 30 segundos (FIGURA 3d),

9- A pinça hemostática foi retirada, a lesão foi inspecionada (FIGURA 3e) e a pele suturada com fio de poliglicol (poliglactina) 3-0 (FIGURA 3f),

10- Foi aplicado álcool iodado $4 \%$ sobre a sutura, que foi deixada exposta e sem a realização de curativos ulteriores,

O mesmo procedimento foi realizado na coxa oposta e após a cirurgia os animais foram colocados em gaiolas. 

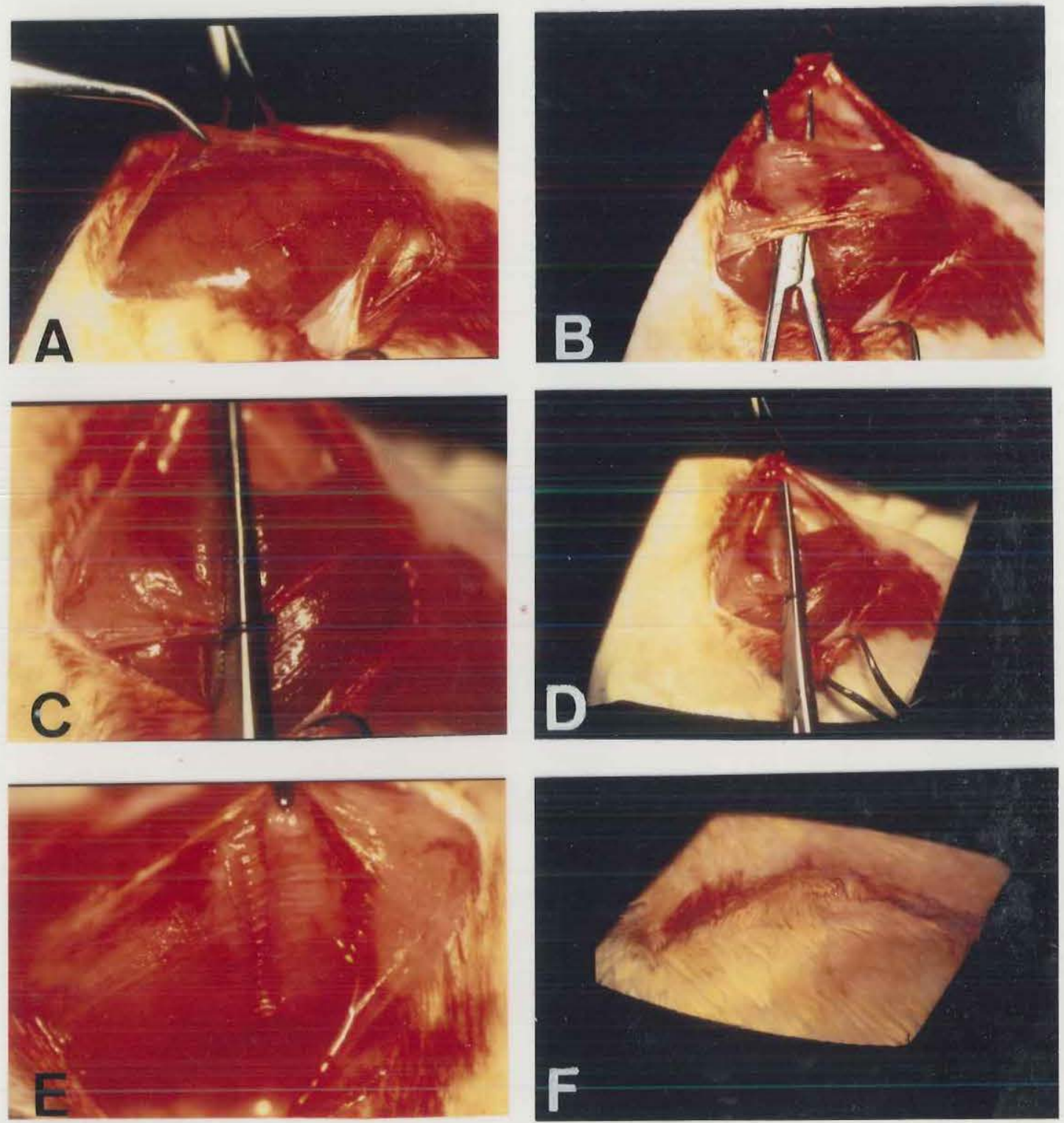

FIGURA 3. Principais etapas cirúrgicas de produção da lesão muscular. A visualização da massa muscular do quadríceps. B - divulsão do músculo reto femoral. C - posicionamento da pinça até a marca padronizada para produzir a lesão. D - esmagamento muscular. E - músculo esmagado com demarcação dos dentes da pinça. E - pele suturada. 


\subsection{Aplicação do ultra-som}

Após 24 horas de lesão, os animais foram submetidos à aplicação de ultrasom por 10 dias consecutivos, no modo pulsado $1: 2(50 \%)$ com freqüência de $1 \mathrm{MHz}$, e intensidade de $0,5 \mathrm{~W} / \mathrm{cm}^{2}$ (SATA), durante 5 minutos.

Antes de cada lote de animais, o aparelho de ultra-som foi calibrado e realizada sua dosimetria com um dosímetro de precisão Ultra Sonic Power Meter, modelo UPM - DT - 1, no Laboratório de Bioengenharia do Departamento de Materiais da Escola de Engenharia de São Carlos (EESC) - USP. Os animais de numeração ímpar tiveram as coxas direitas tratadas e, nos animais de numeração par, foram tratadas as coxas esquerdas. O controle sempre foi a coxa contralateral do mesmo animal, que não recebeu tratamento algum.

O local de aplicação do transdutor foi na face anterior da coxa, sobre a região da lesão. Foi usado gel como meio acoplador e o transdutor foi continuamente movimentado sobre a região.

O equipamento utilizado foi o Sonacel $\mathrm{III}^{\circledR}$. O desenho de seu cabeçote foi especialmente modificado, para melhor adequar o transdutor à coxa do coelho. $\mathrm{O}$ cabeçote tem formato cônico, dirigindo as ondas produzidas por meio de dois refletores planos que provocam diminuição do comprimento de onda e aumento da sua amplitude, não modificando, portanto, a importância de energia liberada. Este tipo de focagem (direcionamento) do som é muito usado em circunstâncias que requerem muita precisão (WILLIAMS, 1983).

Para a aplicação do ultra-som os animais foram colocados em decúbito lateral, sendo restritos nesta posição com ajuda de outra pessoa, que mantinha a 
cintura escapular e o tronco imobilizados. Durante todo o tratamento os animais ficaram despertos.

\subsection{Técnica de injeção de vasos}

Após dois dias do período de tratamento, os animais foram sacrificados com dose excessiva de anestésico. Em seguida, foi realizada laparotomia com incisão xifopúbica, e a aorta abdominal foi abordada, dissecada e canulada no sentido distal com cateter número 6, fixado por fio 5-0. A veia cava inferior também foi seccionada.

Através do cateter, foi feita lavagem do sistema vascular com solução fisiológica introduzida com uma seringa de vidro de $20 \mathrm{ml}$ conectada ao cateter, até que o líquido de refluxo pela veia estivesse límpido (em geral, $500 \mathrm{ml}$ de solução).

Em seguida, foi feita injeção de uma solução de $70 \%$ de sulfato de bário e $30 \%$ de tinta da China (VOLPON \& SANTOS NETO, 1983), através do mesmo cateter e utilizando uma seringa de vidro de $10 \mathrm{ml}$. A pressão de injeção foi controlada de forma manual e empiricamente, buscando o livre fluxo da solução pelo sistema vascular e tentando evitar ruptura de pequenos vasos pela pressão excessiva (em geral, $15 \mathrm{ml}$ de solução).

Após 1 hora, para a adequada fixação do corante, o membro inferior foi amputado proximalmente no ilíaco e no terço médio da perna. A peça resultante foi fixada em solução de formaldeído $10 \%$ por 2 dias. 


\subsubsection{Diafanização}

Completados os dois dias de fixação, foi removida a pele, feita a desarticulação coxo-femoral e desprezado o fragmento pélvico. $\mathrm{O}$ espécime foi colocado em solução de álcool $70 \%$ por 2 dias e em álcool absoluto por 9 dias, com 3 trocas a cada 3 dias.

Para o processo de clarificação propriamente dito, segundo a técnica de Spalteholtz (VOLPON \& SANTOS NETO, 1983), o material transferido do último álcool absoluto para o benzeno puro, e aí permaneceu por 5 dias. O músculo quadríceps foi removido em bloco, realizando o seu descolamento do fềmur e seccionando o tendão patelar.

Em seguida, o músculo reto femoral foi dissecado parcialmente dos outros componentes musculares (FIGURA 4) e, estes amarrados pelas extremidades e fixados em um quadro de aço de $6 \times 12 \mathrm{~cm}$ de modo a preservar o comprimento dos músculos nas etapas seguintes. Estes espécimes foram mantidos em benzeno até que ficassem relativamente transparentes (em geral 1 semana).

Depois disso, o músculo reto femoral foi totalmente separado dos outros componentes e, o músculo foi regularizado de modo a se obterem fatias longitudinais de 2 a 3 milímetros de espessura. Cada fatia foi colocada entre 2 lâminas de vidro que ficaram presas pelas extremidades com clipes metálicos. Este conjunto, lâminas/espécime, foi mantido em benzeno puro por mais 15 dias, onde a diafanização foi completada.

Após a clarificação, os cortes musculares foram examinados em microscópio cirúrgico com aumento de 6 e 10 vezes, mantendo-os imersos em benzeno. 
No exame da peça foi especialmente atentado para detalhes da vascularização e transiluminados por luz proveniente de um negatoscópio odontológico.

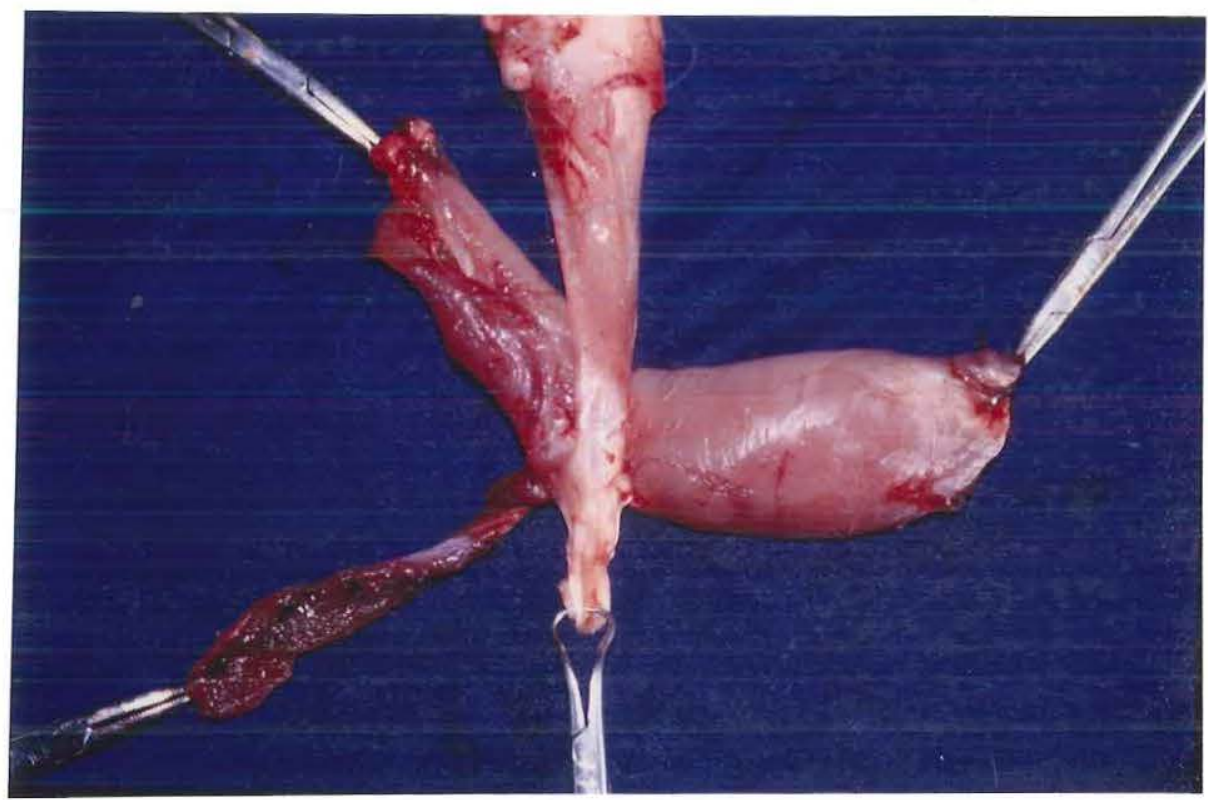

FIGURA 4. Os componentes do músculo quadríceps, separados parcialmente antes de serem amarrados no quadro de aço. 


\section{RESULTADOS}

Os animais toleraram bem o procedimento cirúrgico e, foram capazes de realizar movimentação ativa com os membros posteriores durante todo o período de tratamento.

\subsection{Aspectos Gerais}

Os espécimes apresentaram rica trama vascular, originada a partir de um vaso principal na porção central do músculo, indo da direção proximal para a distal. Deste vaso principal havia divisão de vasos de menor calibre direcionados para a periferia do músculo, dispostos mais ou menos com a mesma orientação (FIGURA 5a). Estes mesmos vasos emitiam outros vasos de menor calibre, e assim sucessivamente, formando a árvore vascular, com amplas conexões anastomóticas entre os vasos de diferentes calibres. Na região próxima do tendão patelar havia diminuição da vascularização.

Outros ramos vasculares independentes penetravam na periferia do músculo e subdividiam-se, realizando conexões anastomóticas com os ramos provenientes do vaso central (FIGURA 5b). 


\subsection{Região da lesão}

Na região da lesão foi observada a presença de derrame difuso de contraste (FIGURAS 6a e 6b). Houve, também, maior quantidade de vasos de pequeno calibre em direções variadas, situados por toda a área da lesão, diferentemente das regiões proximal e distal, caracterizando o aumento de vascularização local.

Na comparação entre os lados, houve semelhança qualitativa em toda a rede vascular, inclusive na região da lesão. Portanto, entre os lados tratados e não tratados, não foram observadas diferenças significativas na rede vascular. 

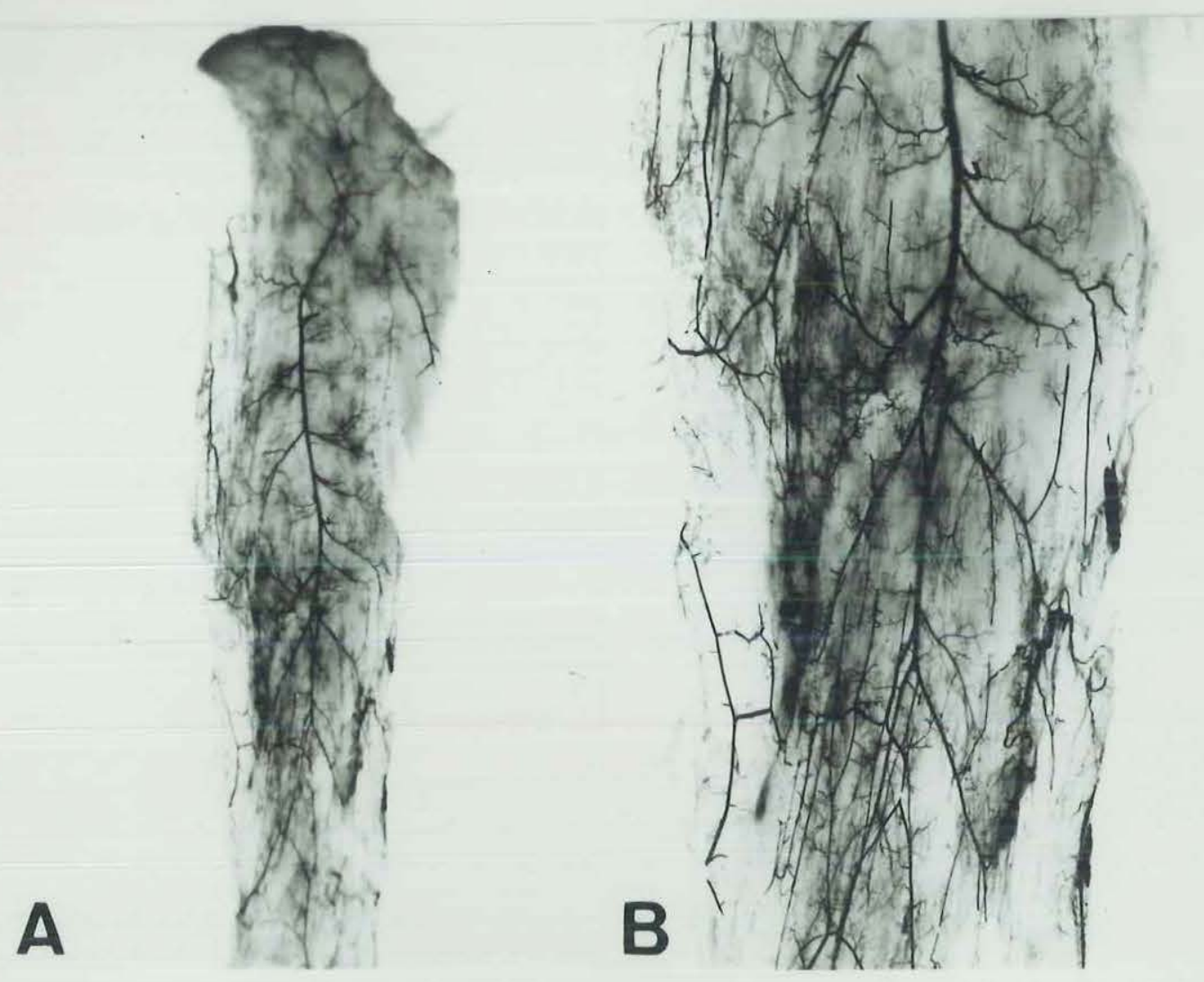

FIGURA 5. A - músculo reto femoral submetido à injeção de vasos. Há um vaso central que penetra na região proximal do músculo e divide-se sucessivamente. Outros ramos penetram pelas bordas do músculo e, por subdivisão, realizam ampla anastomose $(1,5 x)$. B - detalhe da vascularização (5x). 


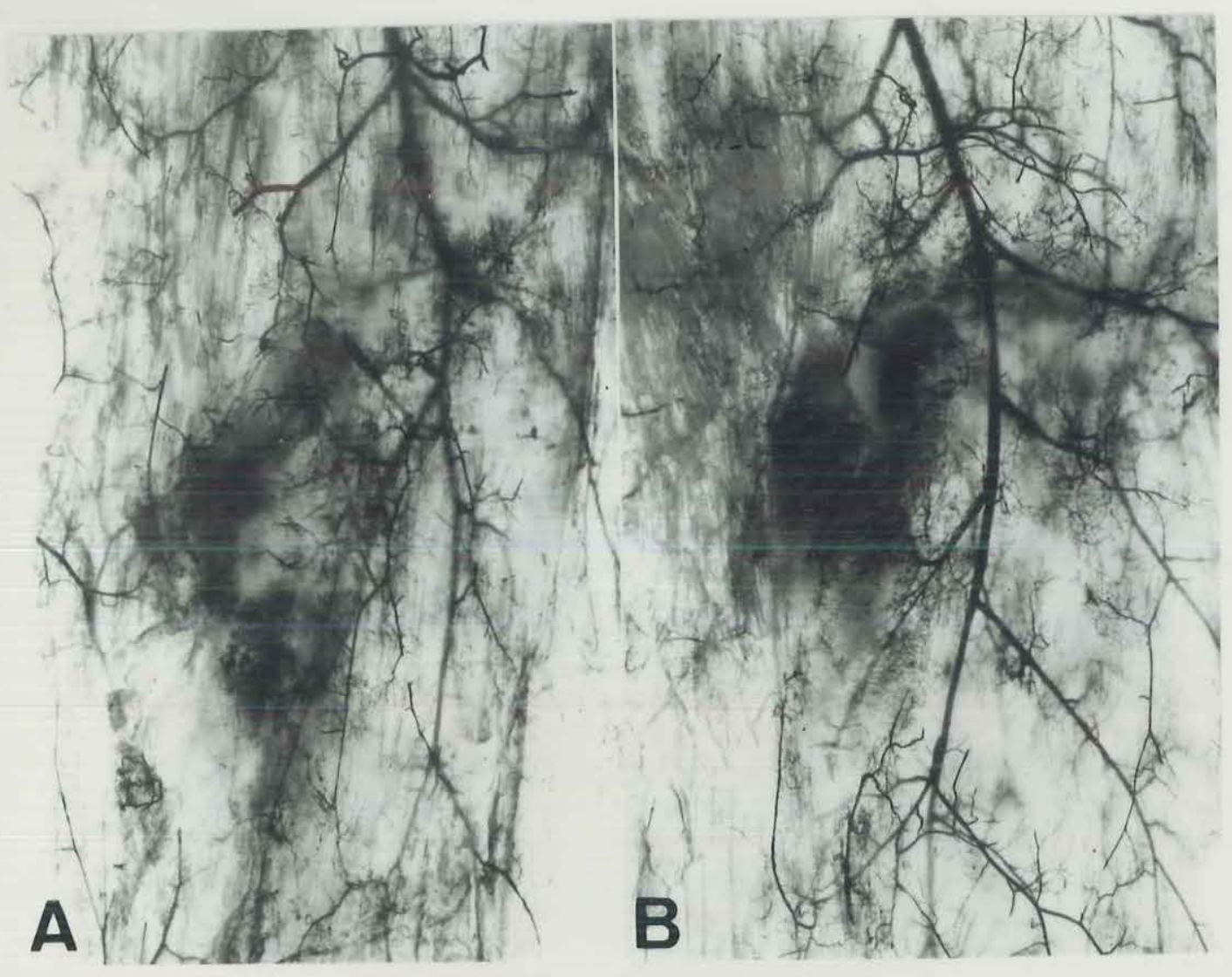

FIGURA 6. Vascularização da região lesada do músculo reto femoral tratado (A) e controle (B). Em ambos músculos há espalhamento do contraste e proliferação vascular com padrão semelhante $(5 x)$. 


\section{DISCUSSÃO}

Nos últimos 50 anos o ultra-som passou a ser largamente utilizado na área médica, tanto para diagnóstico, como na terapêutica. DYSON (1987) afirmou que o ultra-som é um dos recursos clinicamente mais utilizados para reparação de tecidos moles. Neste período, muitos estudos laboratoriais foram realizados para determinar os efeitos terapêuticos ou não do ultra-som. No entanto, há ainda muitas dúvidas e incertezas sobre os seus efeitos. PATRIDGE (1987) afirmou que as evidências de eficácia do ultra-som são baseadas nas experiências clínicas individuais sendo, portanto, necessária a realização de trabalhos com a finalidade de esclarecer quais beneficios o ultra-som poderia trazer.

Dos muitos trabalhos referentes à reparação de tecidos como os de DYSON; POND; JOSEPH (1970); POSPISILOVÁ (1976); DYSON; FRANKS; SUCKLING (1976); ROCHE \& WEST (1984); DYSON (1987); YOUNG \& DYSON (1990b) dentre outros, chama-nos a atenção o aumento da neoformação vascular, que tem sido citada na literatura, baseados no trabalho de YOUNG \& DYSON (1990a) que estudaram de maneira específica a angiogênese e constataram aumento da neoformação de vasos, após o uso do ultra-som. Contudo, esses trabalhos referentes à reparação tecidual e à angiogênese foram realizados somente 
em lesões cutâneas provocadas experimentalmente, ou em lesões pré-existentes como úlceras varicosas.

Para a reparação das lesões musculares, o uso do ultra-som também é muito utilizado e está sempre associado a outros recursos, como mobilizações ativas e passivas, massagens e resfriamento com bolsas de gelo. No âmbito esportivo, onde a incidência destas lesões é maior, é quase impossível aos atletas não serem tratados com ultra-som que, aparentemente tem sido eficiente. Desta forma, interessou-nos investigar se a aplicação do ultra-som terapêutico, poderia provocar mudanças no padrão de neoformação de vasos nas lesões musculares, o que poderia refletir-se no processo de reparação.

A contusão muscular ou esmagamento do músculo foi escolhida como lesão neste trabalho, pois é o tipo mais comum de lesão, sendo também o modelo mais descrito na literatura, juntamente com as lesões por esforço (CRISCO et al., 1994). Os modelos de lesão por esforço foi por nós descartado, pois estas lesões podem ocorrer na região proximal, média e distal, ou ainda, em todas estas regiões (PACHIONI, 1996). Como precisávamos de uma lesão padronizada, em um local, onde houvesse massa muscular e vascularização suficiente para analisarmos, foi adotado o modelo descrito por ALLBROOK (1962), porém com algumas modificações. O tempo de compressão foi menor do que aquele recomendado pelo autor, pois o mesmo causaria uma lesão grave. Nós procuramos simular o máximo possível as condições clínicas e, nestas circunstâncias, as lesões musculares geralmente são leves ou moderadas. Outra modificação foi quanto à escolha do músculo. Pareceu-nos mais interessante utilizar o músculo reto femoral por apresentar boa localização, ser mais superficial, de fácil identificação, ter forma achatada, 
facilitando sua dissecação em relação aos outros componentes musculares, facilitando o procedimento cirúrgico e o processamento da peça. Aliado a estas vantagens, o reto femoral também foi escolhido por ser o quadríceps femoral um dos elementos que mais comumente é sede de lesão (LOPES et al., 1994).

Realizamos a lesão $3 \mathrm{~cm}$ acima do pólo superior da patela com a finalidade de padronização do local e garantir que uma massa suficiente de músculo fosse lesada.

A aplicação do ultra-som ocorreu 24 horas após a lesão, pois foi nossa intenção que fosse realizada na fase aguda de reparação como recomendou OAKLEY (1978) que ressaltou a importância de iniciar a terapêutica por ultra-som o mais cedo possível (entre 24 e 48 horas). Para tanto, utilizamos o ultra-som no modo pulsado, pois ele tem menor produção de calor (DYSON; POND; JOSEPH, 1970; Teer HAAR, 1987) e, assim, evitaria que o processo inflamatório agudo causado pelo traumatismo fosse exacerbado (PATRICK, 1978). Optamos pela taxa de repetição de 1:2 (50\%), porque nosso equipamento fornecia uma intensidade máxima no modo contínuo de $2 \mathrm{~W} / \mathrm{cm}^{2}$ e na taxa de $1: 4(20 \%)$, a intensidade era inferior a que desejávamos. Foi utilizada a freqüência de $1 \mathrm{MHz}$, para atingir tecidos mais profundos como o músculo (DRAPER; CASTEL; CASTEL, 1995). A intensidade de 0,5 W/cm² foi escolhida por ser apontada pela literatura como sendo a mais adequada nesta fase da reparação (DYSON; POND; JOSEPH, 1970; DYSON, 1987; YOUNG \& DYSON, 1990b) sem provocar estase de células sangüíneas (DYSON \& POND, 1973). O tratamento foi realizado com duração de 5 minutos por ser o mais recomendado na literatura (DYSON; POND; JOSEPH, 1970; CLARKE \& STENNER, 1976; POSPISILOVÁ, 1976; HOGAN; BURKE; FRANKLIN, 1982; 
YOUNG \& DYSON, 1990a e YOUNG \& DYSON 1990b). O período de 10 dias consecutivos de tratamento foi realizado buscando simular condições clínicas, além de aproveitar os primeiros dias pós-lesão, onde ocorre a neoformação de vasos (DYSON, 1987; YOUNG \& DYSON, 1990a).

Após o término do período de tratamento aguardamos 2 dias para o sacrificio dos animais para esperar que qualquer efeito transitório do tratamento desaparecesse e, também, ao completar 13 dias de lesão estaria dentro de uma fase (entre 7 e 14 dias) onde as alterações histológicas na cicatrização muscular observadas por HURME et al. (1991) são pequenas, somando-se apenas deposição de colágeno.

A técnica de injeção de vasos e a diafanização foram baseadas no trabalho de VOLPON \& SANTOS NETO (1983), com algumas modificações em relação ao processamento, pois o material demorou mais tempo para clarear.

A motivação deste trabalho foi baseada na pouca exploração do assunto, associados às informações de JÓZSA et al. (1980), LEHTO \& JÄRVINEN (1991) sobre a necessidade da vascularização para reparação muscular, nas afirmações de YOUNG \& DYSON (1990a) sobre a eficácia do ultra-som na neovascularização e, pelos achados de RUBIN et al. (1990) onde o ultra-som foi capaz de produzir um mínimo de redução aguda em $\mathrm{pO}_{2}$ tecidual, indicando que o mesmo pode melhorar a cicatrização. Estes achados estão baseados em KNIGHTON et al. (1981) que demonstraram que um gradiente hipóxico tecidual foi necessário para reparação de feridas e, quando o gradiente é destruído, cessa o crescimento capilar e ainda diferentes gradientes de oxigênio influenciam na densidade e crescimento do capilar. KNIGHTON et al. (1983) afirmaram que este crescimento pode ser influenciado por 
ação dos macrófagos secretando fator angiogênico em resposta à tensão de oxigênio, achados confirmados por JENSEN et al. (1986). Entretanto, nossos resultados mostraram não haver diferenças significativas entre os lados tratado e não tratado, do ponto de vista da vascularização arterial e arteriolar.

Para explicar tais resultados, uma das hipóteses é que o método de avaliação não tenha sido o mais adequado, pois esta técnica preenche o sistema vascular arterial, até arteríolas, excluindo os capilares e veias (VOLPON \& SANTOS NETO, 1983) não detectando alterações morfológicas capilares. Contudo, como observamos nas FIGURAS 6a e 6b, o preenchimento de vasos foi bom e, acreditamos que o método obteve um bom alcance apresentando detalhadamente a vascularização.

$\mathrm{Na}$ fase de experimento piloto, usamos a técnica com acetato de vinila para o preenchimento vascular, que apresentava como vantagem o estudo tridimensional da vascularização. Entretanto, os vasos menores que seriam interessantes observar, não foram preenchidos de maneira homogênea.

A análise qualitativa dos resultados foi realizada por ser o usual no estudo vascular e, na literatura consultada, apenas os trabalhos de LEFAUCHEUR et al., (1996) e YOUNG \& DYSON (1990a) avaliaram a quantidade de vasos, utilizando equipamentos e técnicas que para nós era de dificil acesso e reprodução.

A literatura relacionando efeito do ultra-som e neovascularização, é escassa, sendo citado nos trabalhos de revisão de DYSON (1987) e KITCHEN \& PATRIDGE (1990) de que possa haver correlação entre ambos.

Entretanto, foi em YOUNG \& DYSON (1990a) que este tema foi estudado especificamente, em lesões cutâneas em ratos. Os resultados destes autores mostram que o ultra-som foi efetivo no aumento de neoformação vascular na freqüência de 
$0,75 \mathrm{MHz}$, observado no $5^{\circ}$ dia após a lesão, sendo que no $7^{\circ}$ dia a diferença não foi estatisticamente significante. De certa forma isto pode explicar em parte a divergência dos nossos achados, visto que em nosso trabalho, a retirada do material ocorreu no $13^{\circ}$ dia após a lesão.

Outro fator a ser lembrado é o de que os animais não ficaram imobilizados, podendo locomover-se livremente na gaiola. Isto pode ter gerado uma variável, pois JÄRVINEN (1976) informou que o crescimento vascular após esmagamento muscular em ratos, foi maior e mais rápido nos animais mobilizados do que nos imobilizados, especialmente na $1^{\mathrm{a}}$ semana após a lesão. Esta variável, portanto, pode ter influenciado em nossos resultados, tornando o processo de neovascularização semelhante entre os lados.

Embora o método possa ter sido ineficaz em demonstrar alterações e haver a presença de uma possível variável não controlada, não podemos deixar de considerar que os resultados possam ser legítimos.

Nos trabalhos relacionados com a reparação tecidual e ultra-som, percebemos que os efeitos bem conhecidos e estabelecidos são o aumento na síntese de DNA ( DYSON; POND; JOSEPH, 1970; POSPISILOVÁ, 1976), alterações na membrana celular (DYSON \& SUCKLING, 1978; DYSON, 1987; YOUNG \& DYSON, 1990b; KITCHEN \& PATRIDGE, 1990), síntese de proteínas (POSPISILOVÁ, 1976; DYSON \& SUCKLING, 1978; ROCHE \& WEST, 1984; DYSON, 1987; KITCHEN \& PATRIDGE, 1990), aumento do cálcio intracelular (DYSON, 1987; KITCHEN \& PATRIDGE, 1990; YOUNG \& DYSON, 1990b), estimulação de fibroblastos e desgranulação de macrófagos (DYSON, 1987; YOUNG \& DYSON; 1990b). No trabalho de YOUNG \& DYSON (1990a), relacionado com a 
angiogênese, a explicação para seus resultados foi direcionada basicamente para o fato do ultra-som provocar desgranulação de macrófagos levando à formação ou liberação de fatores angiogênicos e fatores de crescimento de fibroblastos, mediante microfluxo ou cavitação estável.

Afinal, o ultra-som tem eficácia na prática clínica por sua bem conhecida ação sobre os fibroblastos, ou além disto produz neovascularização ? Ou, ainda, há associação entre estes eventos?

Todos estes efeitos atribuídos ao tratamento ultra-sônico são dependentes de mediadores químicos e mecanismos moleculares e estes não são bem conhecidos. DYSON \& SUCKLING (1978) afirmaram que havia desconhecimento do efeito do ultra-som sobre outras células que não o fibroblastos. MAXWELL (1992) deixou claro que, quando se procura associar os efeitos do ultra-som aos mecanismos celulares e moleculares, muitas divergências são encontradas na literatura em relação a microcirculação, mediadores inflamatórios, infiltração celular e na reparação aguda e crônica, sendo necessário mais investigações.

GAM \& JOHANNSEN (1995) fizeram revisão de 293 trabalhos publicados desde 1950, sobre a eficácia do ultra-som no tratamento das desordens músculoesqueléticas, mediante meta-análise. Constataram que apenas 22 destes trabalhos descreviam provas comparando tratamento ultra-sônico, tratamento não ultra-sônico, placebo e grupos não tratados. Em 16 trabalhos, foram comparados resultados entre ultra-som e placebo, e somente em 13 casos foi encontrada uma associação possível.

Os autores encontraram, em apenas 9 trabalhos, evidências que o ultra-som tenha sido o responsável pelos achados e concluíram que o tratamento ultra-sônico está baseado em experiências empíricas. 
Diante destas considerações e de nossos achados, fica evidente a necessidade de mais investigações para determinar como o ultra-som pode atuar na reparação de lesões musculares, bem como seus mecanismos. Queremos ressaltar os resultados de MENEZES (1997) que encontrou melhora das propriedades mecânicas em músculos lesados e tratados pelo ultra-som. Estudos histológicos e outras formas de identificação de vasos, devem ser utilizados para tentar esclarecer a possível relação ultra-som e a angiogênese. 


\section{CONCLUSÃO}

Os resultados do presente trabalho, sugerem que o ultra-som não provocou mudanças no padrão vascular (artérias e arteríolas) após aplicação precoce em lesões musculares, com os parâmetros ultra-sônicos e metodologia empregados. 


\section{REFERÊNCIAS BIBLIOGRÁFICAS}

ALLBROOK, D. (1962). An electron microscopic study of regenerating skeletal muscle. J. Anat. Lond., v. 96, n.2, p.137-52.

CARAZZATO, J.G. (1994). Lesões musculotendíneas e seu tratamento. Rev. Bras. Ortop., v.29, n.10, p.723-28.

CARLSON, B.M.; FAULKNER, J.A. (1983). The regeneration of skeletal muscle fibres following injury: a review. Med. Sci. Sports Exerc., v.15, n. 3, p.187-98.

CLARKE, G.R.; STENNER, L. (1976). Use of therapeutic ultrasound. Physiotherapy, v.62, n. 6, p.185-90.

CRISCO, J.J.; JOKL, P.; HEINEN, G.T.; CONNELL, M.D.; PANJABI, M.M. (1994). A Muscle contusion injury model. Am. J. of Sports Medicine, v.22, n.5, p.702-10.

DRAPER, D.O.; CASTEL, J.C.; CASTEL, D. (1995). Rate of temperature increase in human muscle during $1 \mathrm{MHz}$ and $3 \mathrm{MHz}$ continuous ultrasound. $J$. Orthop. Sports Phys. Ther., v.22 n.4, p.142-50.

DYSON, M. (1987). Mechanisms involved in therapeutic ultrasound. Physiotherapy, v.73, n.3, p.116-20.

DYSON, M.; FRANKS, C.; SUCKLING J. (1976). Stimulation of healing of varicose ulcers by ultrasound. Ultrasonics, v.14, p.232-36.

DYSON, M.; POND, J.B. (1973). The effects of ultrasound on circulation. Physiotherapy, v.59, n.9, p.284-87.

DYSON, M.; POND, J.B.; JOSEPH, J. (1970). Stimulation of tissue regeneration by pulsed plane-wave ultrasound. IEEE Trans. Sonics Ultrasonics, v.17, n.3, p.133-40.

DYSON, M.; SUCKLING, J. (1978). Stimulation of tissue repair by ultrasound: a survey of mechanisms involved. Physiotherapy, v.64, n.4, p.105-08.

ENWEMEKA, C.S. (1989). The effects of therapeutic ultrasound on tendon healing: a biomechanical study. Am. J. Phys. Med. Rehabil., v.68, n.6, p.283-87.

FISHER, B.D.; BARACOS, V.E.; SHNITKA, T.K.; MENDRYK, S.W.; REID, D.C. (1990). Ultrastructural events following acute muscle trauma. Med. Sci. Sports Exerc., v.22, n.2, p.185-93.

GAM, A N.; JOHANNSEN, F. (1995). Ultrasound therapy in musculoskeletal disorders: a meta-analysis. Pain, v.63, p.85-91. 
HOGAN, R.D.; BURKE, K.M.; FRANKLIN, T.D. (1982). The effect of ultrasound on microvascular hemodynamics in skeletal muscle: effects during ischemia. Microvascular Research, v.23, p.370-79.

HURME, T.; KALIMO H.; LEHTO, M.; JÄRVINEN, M. (1991). Healing of skeletal muscle injury: an ultrastructural and immunohistochemical study. Med. Sci. Sports Exerc., v.23, n.7, p.801-10.

JÄRVINEN, M. (1976). Healing of crush injury in rat striated muscle. Acta Path. Microbiol. Scand., v.84, p.85-94.

JENSEN, J.A; HUNT, T.K.; SCHEUENSTUHL, H.; BANDA M.J. (1986). Effect of lactate, pyruvate, and $\mathrm{pH}$ on secretion of angiogenesis and mitogenesis factors by macrophages. Laboratory Investigation, v.54, n.5, p.574-78.

JÓZSA, L; RÉFFY, A.; DEMEL, S.; SZILÁGYI, I. (1980). Alterations of oxygen and carbon dioxide tensions in crush-injured calf muscles of rat. Z. Exper. Chirurg., v.13, p.91-94.

KITCHEN, S.S.; PARTRIDGE C.J. (1990). A review of therapeutic ultrasound. Physiotherapy, v.76, n.10, p.593-600.

KNIGHTON, D.R.; SILVER I.A; HUNT T.K. (1981). Regulation of wound healing angiogenesis - effect of oxygen gradientes and inspired oxygen concentration. Surgery, v.90, n.2, p.262-70.

KNIGHTON, D.R.; HUNT, T.K.; SCHEUENSTUHL, H.; HALLIDAY, B.J. (1983). Oxygen tension regulates the expression of angiogenesis factor by macrophages. Science, v.221, p.1283-285.

KREMKAU; F.W. (1985). Physical considerations. In: NYBORG, L.N.; ZISKIN, M.C. Biological effects of ultrasound. New York, Churchill Livingstone. Cap.2, p.9-21.

LEFAUCHEUR, J.P.; GJATA, B.; LAFONT, H.; SEBILLE, A. (1996). Angiogenic and inflammatory responses following skeletal muscle injury are altered by immune neutralization of endogenous basic fibroblast growth factor, insulin-like growth factor-1 and transforming growth factor-beta 1. J. Neuroimmunol., v.70, n. 1, p.37-44.

LEHMANN, J. F. (1953). The biophisical mode of action of biologic and therapeutic ultrasonic reactions. The Journal of the Acoustical Society of América, v.25, n.1, p.17-25.

LEHTO, M.U.K.; JÄRVINEN, M.J. (1991). Muscle injuries, their healing process and treatment. Annales Chirurgiae et Gynaecologiae, v.80, n.2, p.102-08.

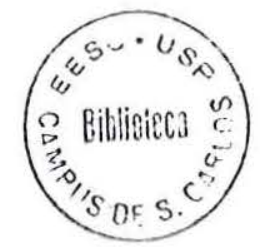


LOPES, A. S.; KATTAN, R.; COSTA, S.; MOURA, C.E. (1993). Estudo clínico e classificação das lesões musculares. Rev. Bras. Ortop., v.28, n.10, p.707-17.

LOPES, A. S.; KATTAN, R.; COSTA, S.; MOURA, C.E.; LOPES, R.S. (1994). Diagnóstico e tratamento das contusões musculares. Rev. Bras. Ortop., v. 29, n. 10, p.714-22.

MAXWELL, L. (1992). Therapeutic ultrasound: Its effects on the celular and molecular mechanisms of inflamation and scar. Physiotherapy, v.78, n.6, p.42126.

MENEZES, D.F. (1997). Aplicação do Ultra-som Terapêutico em Lesão Muscular Experimental Aguda. Ribeirão Preto. 64p. Dissertação (Mestrado) Escola de Engenharia de São Carlos /Faculdade de Medicina de Ribeirão Preto, Universidade de São Paulo.

NIKOLAOU, P.K.; MACDONALD, B.L.; GLISSON, R.R.; SEABER, A.V.; GARRETT, W.E. (1987). Biomechanical and histological evaluation of muscle after controlled strain injury. Am. J. of Sports Medicine, v.15, n.1, p.9-14.

OAKLEY, E.M. (1978). Application of continuous beam ultrasound at therapeutic levels. Physiotherapy, v.64, n.6, p.169-70.

PAASKE, W.P.; HOVIND, H.; SEJRSEN, P. (1973). Influence of ultrasonic irradiation on bood flow in human cutaneous, subcutaneous, and muscular tissues. Scand. J. clin. Lab. Invest., v.31, p.389-94.

PACHIONI, C.A.S. (1996). Lesão por estiramento do músculo soleus: estudo experimental em ratos. Ribeirão Preto. 60p. Dissertação (Mestrado) Escola de Engenharia de São Carlos /Faculdade de Medicina de Ribeirão Preto, Universidade de São Paulo.

PATRICK, M.K. (1978). Applications of therapeutic pulsed ultrasound. Physiotherapy, v.64, n.4, p.103-04.

PARTRIDGE, C.J. (1987). Evaluation of the efficacy of ultrasound. Physiotherapy, v.73, n. 4, p.166-68.

POSPISILOVÁ, J. (1976). Effect of ultrasound on collagen synthesis and deposition in experimental granuloma tissue. Possibilities of clinical uses of ultrasound in healing disorders. Acta Chirurgiae Plasticae, v.18, n.4, p.176-83.

RANTANEN, J.; HURME, T.; LUKKA, R.; HEINO, J.; KALIMO, H. (1995). Satellite cell proliferation and the expression of myogenin and desmin in regenerating skeletal muscle: Evidence for two different populations of Satellite cells. Laboratory Investigation, v.72, n.3, p.341-47. 
ROBINSON, S.E.; BUONO, M.J. (1995). Effect of continuous-wave ultrasound on flow in skeletal muscle. Physical Therapy, v.75, n.2, p.145-49.

ROCHE C.; WEST, J. (1984). A controlled trial investigating the effect of ultrasound on venous ulcers referred from general practioners. Physiotherapy, v.70, n. 12, p. $475-77$.

RUBIN, M.J.; ETCHISON M.R; CONDRA, K.A.; FRANKLIN JR, T.D.; SNODDY, A M. (1990). Acute effects of ultrasound on skeletal muscle oxigen tension, blood flow and capillary density. Ultrasound Med. Biol., v.16, n.3, p. 271 -77 .

Teer HAAR, G. (1978). Basic physics of therapeutic ultrasound. Physiotherapy, v.64, n. 4, p. $100-03$.

Teer HAAR, G. (1987). Basic physics of therapeutic ultrasound. Physiotherapy, v.73, n. 3, p.110-13.

VOLPON, J.B.; SANTOS NETO, F.L. (1983). Injeção de corantes nos vasos ósseos. Algumas considerações práticas. Rev. Bras.. Ortop., v.18, n.6, p.205-07.

WILLIAMS, A R. (1983). Ultrasound: biological effects and potential hazards. 2.ed. London. Academic Press.

WILLIAMS, R. (1987). Production and transmission of ultrasound. Physiotherapy, v.73, n.3, p.113-16.

YOUNG, S.R.; DYSON, M. (1990a). The effect of therapeutic ultrasound on angiogenesis. Ultrasound Med. Biol., v.16, n.3, p.261-69.

YOUNG, S.R.; DYSON, M. (1990b). Macrophage responsiveness to therapeutic ultrasound. Ultrasound Med. Biol., v.16, n.8, p.809-16. 